\title{
Development of Damage Resistant Sputtered Oxide Optical Coatings for Use at 248 NM
}
W. T. Pawlewicz
P. M. Martin
D. D. Hays
I. B. Mann

October 1981

Prepared for

the Lawrence Livermore National Laboratory under a Related Services Agreement with the U.S. Department of Energy

Contract DE-ACO6-76RLO 1830

Pacific Northwest Laboratory Operated for the U.S. Department of Energy by Battelle Memorial Institute 


\title{
NOTICE
}

This report was prepared as an account of work sponsored by the United States Government. Neither the United States nor the Department of Energy, nor any of their employees, nor any of their contractors, subcontractors, or their employees. makes any warranty. express or implied, or assumes any legal liability or responsibility for the accuracy, completeness or usefulness of any information, apparatus. product or process disclosed, or represents that its use would not infringe privately owned rights.

The views. opinions and conclusions contained in this report are those of the contractor and do not necessarily represent those of the United States Government or the United States Department of Energy.

\author{
PACIFIC NORTHWEST LABORATORY \\ operated by \\ BATTELLE \\ for the \\ UNITED STATES DEPARTMENT OF ENERGY \\ Under Contract DE-AC06-76RLO 1830
}

\author{
Printed in the United States of America \\ Available from \\ National Technical Information Service \\ United States Department of Commerce \\ 5285 Port Royal Road \\ Springfield, Virginia 22151
}

Price: Printed Copy $\mathbf{S}$

$\because$ Microfiche $\$ 3.00$

- Pages Selling Price

\begin{tabular}{ll}
\hline $001-025$ & $\$ 4.00$ \\
$026-050$ & $\$ 4.50$ \\
$051-075$ & $\$ 5.25$ \\
$076-100$ & $\$ 6.00$ \\
$101-125$ & $\$ 6.50$ \\
$126-150$ & $\$ 7.25$ \\
$151-175$ & $\$ 8.00$ \\
$176-200$ & $\$ 9.00$ \\
$201-225$ & $\$ 9.25$ \\
$226-250$ & $\$ 9.50$ \\
$251-275$ & $\$ 10.75$ \\
$276-300$ & $\$ 11.00$
\end{tabular}




\section{1}

PNL -3869

UC -21

DEVELOPMENT OF DAMAGE RESISTANT

SPUTTERED OXIDE OPTICAL COATINGS

FOR USE AT 248 NM

W.T. Pawlewicz

P.M. Martin

D.D. Hays

I.B. Mann

October 1981

Prepared for

the Lawrence Livermore National Laboratory under a Related Services Agreement with the U.S. Department of Energy Contract DE-ACO6-76RLO 1830

Pacific Northwest Laboratory

Richland, Washington 99352 
. 


\section{SUMMARY}

This report summarizes the results of a six-month effort to develop damage-resistant $K r * F$ laser mirrors by using and refining reactive sputter deposition techniques for the fabrication of multilayer oxide optical coatings. Mirror performance goals included a reflectivity of $99 \%$ at $248 \mathrm{~nm}$ and a laser damage threshold of $5 \mathrm{~J} / \mathrm{cm}^{2}$ for $20 \mathrm{~ns}$ pulses. Above and beyond these goals, however, particular attention was to be paid to improvement of the physical and optical properties of the coatings with the goal of extending to shorter wavelengths the ultraviolet absorption edge of candidate multilayer combinations.

Oxide multilayer coating combinations selected for development were $\mathrm{SiO}_{2} / \mathrm{Al}_{2} \mathrm{O}_{3}, \mathrm{SiO}_{2} / \mathrm{HfO}_{2}$ and $\mathrm{SiO}_{2} / \mathrm{Y}_{2} \mathrm{O}_{3}$. Selection was based on review and compilation of the optical properties of oxide materials reported in the recent literature. Twenty-eight coatings of selected designs were fabricated on LLNL substrates for laser damage testing by LLNL. Forty other coatings were fabricated on PNL substrates for optical, microstructural and topographical characterization by PNL aimed at optimization of their performance. Specimens for damage testing consisted of single layers of $\mathrm{Al}_{2} \mathrm{O}_{3}, \mathrm{HfO}_{2}$ and $\mathrm{Y}_{2} \mathrm{O}_{3}$ in thicknesses of $\lambda / 2,3 \lambda / 2$ and $2 \lambda$ at $248 \mathrm{~nm}$ plus high reflectors of the design $L L(H L)^{m}$ HLL. In this design each layer is $\lambda / 4$ at $248 \mathrm{~nm}, \mathrm{~L}$ is always $\mathrm{SiO}_{2}$, and $\mathrm{m}=19,10$ and 6 when $\mathrm{H}$ is $\mathrm{Al}_{2} \mathrm{O}_{3}, Y_{2} \mathrm{O}_{3}$ and $\mathrm{HfO}_{2}$, respectively.

Highest reflectivities at $248 \mathrm{~nm}$ were obtained for the $\mathrm{HfO}_{2} / \mathrm{SiO}_{2}$ combination for which the multipoint average of readings taken across the face of the 2-inch substrates was $94-96 \%$. Reflectivities in excess of $99 \%$ were obtained in some regions of some of these mirrors. Average reflectivities for $\mathrm{Al}_{2} \mathrm{O}_{3} / \mathrm{SiO}_{2}$ and $\mathrm{Y}_{2} \mathrm{O}_{3} / \mathrm{SiO}_{2}$ were $80-83 \%$ and $62-80 \%$, respectively. 
Highest damage thresholds were obtained for $\mathrm{Al}_{2} \mathrm{O}_{3} / \mathrm{SiO}_{2}$ and were always between 2.0 and $2.3 \mathrm{~J} / \mathrm{cm}^{2}$ for $20 \mathrm{~ns}$ pulses. For $\mathrm{HfO}_{2} / \mathrm{SiO}_{2}$ thresholds ranged from 0.9 to $2.1 \mathrm{~J} / \mathrm{cm}^{2}$, and for $\mathrm{Y}_{2} \mathrm{O}_{3} / \mathrm{SiO}_{2}$ from 0.4 to $0.7 \mathrm{~J} / \mathrm{cm}^{2}$. Thus there was no obvious correlation between damage threshold and the reflectivity. The thresholds of the multilayer mirrors were also found to be very similar to those for single layer coatings. These were 1.5 to $3.2 \mathrm{~J} / \mathrm{cm}^{2}$ for $\mathrm{Al}_{2} \mathrm{O}_{3}, 0.3$ to 0.8 for $\mathrm{HfO}_{2}$, and 0.3 to 1.1 for $\mathrm{Y}_{2} \mathrm{O}_{3}$. No evidence was found for two-photon damage processes from the threshold variation with absorption edge for these three coating materials. Damage resistance did not appear to depend on: (1) single-layer thickness, (2) stack tuned wavelength, (3) laser beam polarization, (4) substrate polishing technique, or (5) substrate cleaning technique. It did appear, however, that significant improvement in damage resistance could come from increased attention to coating cleanliness.

The low mirror reflectivities are due primarily to scattering by columnar surface features caused by insufficient control of the coating grain size. The damage thresholds for both single layers and multilayers may also be governed by the coating surface roughness. Scattering contributed by substrate roughness did not appear to be small. Thus the levels of stoichiometry and purity achieved appear to be adequate, and absorption due to intrinsic interband mechanisms does not appear to be important for any of these materials at $248 \mathrm{~nm}$.

A1 though these results are short of the $99 \%$ and $5 \mathrm{~J} / \mathrm{cm}^{2}$ reflectivity and damage threshold goals of this work, optimization of the deposition of these coating materials to reduce surface roughness and scattering promises to yield improved performance.

Specific recommendations for minimizing coating surface roughness and for correcting other shortcomings of this mirror fabrication effort have been developed to guide future research. 


\section{CONTENTS}

Page

SUMMARY

i i i

FIGURES

vi

TABLES

vi i

INTRODUCTION

EXPERIMENT

Sputtering System ..................... 3

Substrate Preparation . . . . . . . . . . . . 3

Coating Designs . . . . . . . . . . . . . . . 4

Coating Deposition .................. . . 4 4

Coating Characterization .............. 5

RESULTS . . . . . . . . . . . . . . . . . . . . 5

Laser Damage Thresholds . . . . . . . . . . . . . 5

Mirror Reflectivities . . . . . . . . . . . . . . . 7

Single Layer Optical Properties . . . . . . . . . . . . . 9

Coating Microstructural Properties ............ 11

DISCUSSION . . . . . . . . . . . . . . . . . 12

Overview . . . . . . . . . . . . . . . 12

$\mathrm{HfO}_{2} / \mathrm{SiO}_{2}$ mirrors..................... 13

$\mathrm{Y}_{2} \mathrm{O}_{3} / \mathrm{SiO}_{2}$ mirrors . . . . . . . . . . . . . . . . . 14

$\mathrm{Al}_{2} \mathrm{O}_{3} / \mathrm{SiO}_{2}$ mirrors . . . . . . . . . . . . . . . . 15

CONCLUSIONS . . . . . . . . . . . . . . . . 16

RECOMMENDATIONS FOR FURTHER STUDY . . . . . . . . . . . . 18

ACKNOWLEDGEMENTS . . . . . . . . . . . . . . . . . . 19

REFERENCES . . . . . . . . . . . . . . . . . . 20

APPENDIX: "Oxide Optical Coatings for U1traviolet" Literature Survey A-1 


\section{FIGURES}

1. Schematic diagram of $\mathrm{rf}$ diode sputtering system used for coating deposition............... 28

2. Damage thresholds of PNL sputtered coatings at $248 \mathrm{~nm}, 20 \mathrm{~ns} .+29$

3. Lack of correlation between damage threshold and mirror reflectivity. ................ 30

4. Lack of correlation between damage threshold and mirror tuned wavelength. ................ 31

5. Lack of correlation between damage threshold and single-layer coating thickness, $\mathrm{O}_{2}$ partial pressure or substrate cleaning

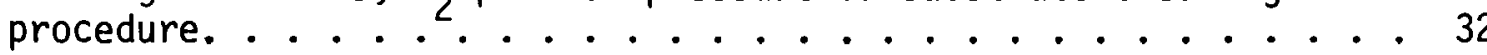

6. Intragroup correlation between damage threshold and coating "cleanliness" ranking. . . . . . . . . . . . . . . . 33

7. Variation of reflectivity of $\mathrm{Al}_{2} \mathrm{O}_{3} / \mathrm{SiO}_{2}$ mirrors with tuned

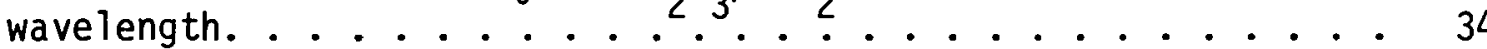

8. Variation of reflectivity of $\mathrm{HfO}_{2} / \mathrm{SiO}_{2}$ mirrors with tuned

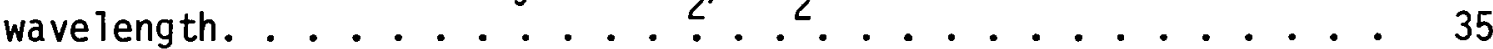

9. Variation of reflectivity of $\mathrm{Y}_{2} \mathrm{O}_{3} / \mathrm{SiO}_{2}$ mirrors with tuned

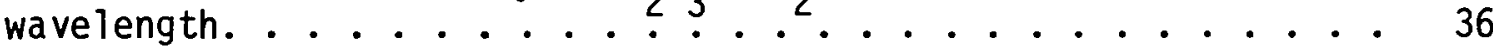

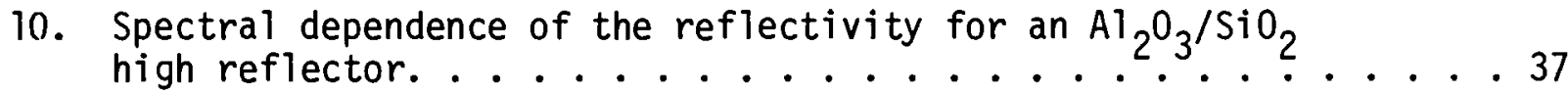

11. Spectral dependence of the reflectivity for a $\mathrm{HfO}_{2} / \mathrm{SiO}_{2}$

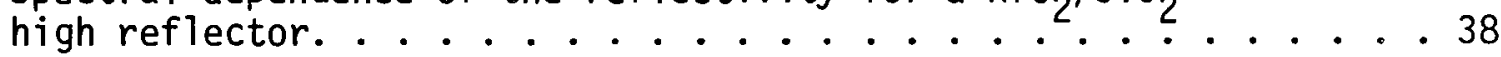

12. Spectral dependence of the reflectivity for an $\mathrm{Y}_{2} \mathrm{O}_{3} / \mathrm{SiO}_{2}$

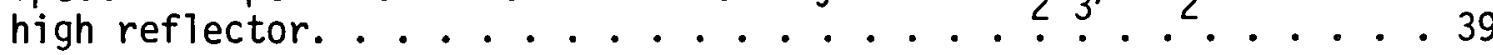

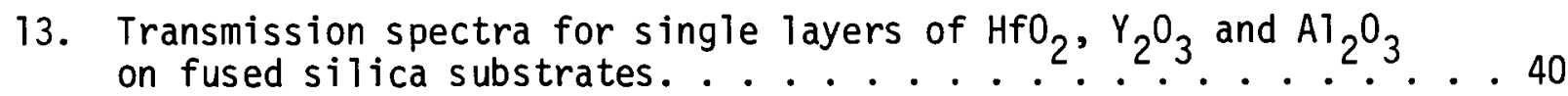

14. Dependence of $\mathrm{Al}_{2} \mathrm{O}_{3}$ scattering/absorption loss at $248 \mathrm{~nm}$ on single-layer coating thickness................... 41

15. Dependence of $Y_{2} \mathrm{O}_{3}$ scattering/absorption loss at $248 \mathrm{~nm}$ on single-layer coating thickness. . . . . . . . . . . . 42

16. Dependence of $\mathrm{HfO}_{2}$ scattering/absorption loss at $248 \mathrm{~nm}$ on single-layer coating thickness. 
17. Dependence of $\mathrm{SiO}_{2}$ scattering/absorption loss at $248 \mathrm{~nm}$ on single-layer coating thickness. . . . . . . . . . . 44

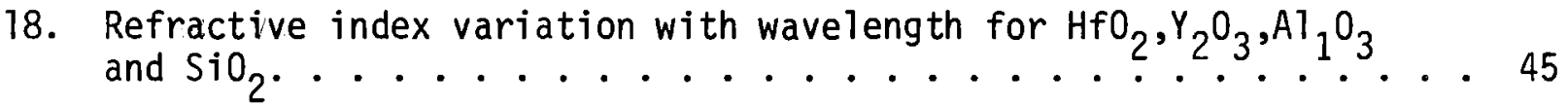

19. Reflectivity and tuned wavelength profile for a typical two-inch diameter $\mathrm{HfO}_{2} \mathrm{SiO}_{2}$ mirror. Note the radial dependence of the reflectivity.................. 46

20. Influence of grain size on transmission loss due to scattering at $248 \mathrm{~nm}$ for approximately constant coating thickness of $2500 \AA$. . 47

21. SEM micrograph of the surface topography of a 23-1ayer $\mathrm{Y}_{2} \mathrm{O}_{3} / \mathrm{SiO}_{2}$

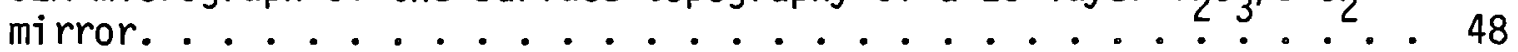




\section{TABLES}

1. Vendor, fabrication method and purity of sputtering targets. . . . 21

2. Sputter deposition conditions for all coatings damage tested. . . 22

3. Damage thresholds of PNL sputtered coatings at $248 \mathrm{~nm}, 20 \mathrm{~ns} . . .23$

4. Absorption and extinction coefficients at $248 \mathrm{~nm}$ for each coating material deduced from Figures 14 through 17. The values for $\mathrm{HfO}_{2}$, $\mathrm{Y}_{2} \mathrm{O}_{3}$ and $\mathrm{Al}_{2} \mathrm{O}_{3}$ are upper limits as explained in the text. . . . . 24

5. Fit parameters for least squares analysis of refractive index dispersion according to the relation $n^{2}=1+\left(A /\left(1-B / \lambda^{2}\right)\right) . . .25$

6. Microstructural properties deduced from x-ray diffractometer data for single layers. . . . . . . . . . . . . 26

7. Transmission and absorption/scattering losses for high reflectors with tuned wavelengths near $248 \mathrm{~nm}$ made from three coating material combinations................. 


\section{INTRODUCTION}

The objective of this work was the development of damage-resistant all-dielectric high reflectors for $K{ }^{\star} \mathrm{F}$ lasers through the use and refinement of reactive sputter deposition techniques for the fabrication of multilayer oxide optical coatings. Specific performance goals included a reflectivity of $99 \%$ at $248 \mathrm{~nm}$ and a damage threshold of $5 \mathrm{~J} / \mathrm{cm}^{2}$ for $20 \mathrm{~ns}$ pulses. Particular attention was also to be paid to determination of coating physical properties or characteristics which limit their optical performance at ultraviolet wavelengths and to extension of the ultraviolet absorption edge to shorter wavelengths.

The work was carried out in three phases: (1) review and compilation of the recent literature for optical and physical properties of oxides leading to selection of $\mathrm{HfO}_{2}, \mathrm{Al}_{2} \mathrm{O}_{3}, \mathrm{Y}_{2} \mathrm{O}_{3}$ and $\mathrm{SiO}_{2}$ as the most promising candidates, (2) deposition of single layer coatings of $\mathrm{HfO}_{2}, \mathrm{Al}_{2} \mathrm{O}_{3}$ and $\mathrm{Y}_{2} \mathrm{O}_{3}$ in integer multiples of half-wave thickness and (3) fabrication of multilayer high reflectors from combinations of $\mathrm{HfO}_{2} / \mathrm{SiO}_{2}, \mathrm{Al}_{2} \mathrm{O}_{3} / \mathrm{SiO}_{2}$ and $\mathrm{Y}_{2} \mathrm{O}_{3} /$ $\mathrm{SiO}_{2}$. Al1 coatings for damage testing were prepared on fused silica or Bk7 glass substrates provided by LLNL and were shipped to LLNL. The coatings shipped and many others made on PNL substrates were characterized for optical, microstructural and topographical features with the intent of understanding the ultimate performance of each coating material in a high reflector stack and optimizing the performance of those stacks. However, it was recognized early on that limited time and funding would allow only a cursory optimization of each coating material and the multilayer reflectors made from them, and that a more detailed examination might be necessary as a follow-on effort. 
This report summarizes all work conducted to date on sputtered oxides for use at the $K{ }^{\star} * F$ wavelength. The Experimental section describes the deposition of single and multilayer oxide optical coatings by reactive sputtering and characterization of their optical and microstructual properties. Deposition and characterization are described in sufficient detail that the work could be repeated elsewhere and so that this report can serve as a starting point for a follow-on effort, should one be desired. Coating designs selected for damage testing are also described. The Results section summarizes in graphs and tables the most important optical property, structural property, and reflectivity data accumulated to date and all laser damage testing data received from LLNL. The Discussion section explains the ultraviolet optical properties of the coatings and the observed performance of the high reflector stacks. The Conclusion section summarizes all key results and is followed by Recommendations for Further Study. Finally, the complete compilation of optical and physical data accumulated in the literature survey of ultraviolet-transmitting oxide materials is included in this report as an Appendix. 
EXPERIMENT

\section{Sputtering System}

All coatings were deposited in $\mathrm{rf}$ diode sputtering systems of the type shown schematically in Figure 1. The systems contained two water-cooled 6-inch diameter sputtering targets, a water-cooled substrate table which was rotated from one target to the next, and rotatable shutters for cleaning targets before deposition and for precise control of coating thickness. Substrate-target spacing was 1.5 inch. One target position was always occupied by the $\mathrm{SiO}_{2}$ target. The second position was used for $\mathrm{HfO}_{2}, \mathrm{Al}_{2} \mathrm{O}_{3}$ or $\mathrm{Y}_{2} \mathrm{O}_{3}$. Material, method of fabrication, vendor and purity of each target are summarized in Table 1. Each target was connected through an $r f$ impedance matching network to an $r f$ power supply operating at $13.56 \mathrm{MHz}$. Target power was typically $600 \mathrm{~W}$. The matching network was always tuned for minimum reflected power.

Coatings were sputtered in atmospheres of $\mathrm{Ar}\left(99.9999 \%\right.$ pure) and $\mathrm{O}_{2}$ (99.9995\% pure). Ar and $0_{2}$ were introduced to the system through flow meters and needle valves. Typical flows were $5 \mathrm{SCCM} / \mathrm{min}$. Gases were mixed and the total pressure was measured with an absolute capacitance manometer. Typical sputtering pressure was 20 mTorr of which $15 \%$ was $0_{2}$, al though some $\mathrm{Al}_{2} \mathrm{O}_{3}$ depositions were made with $50 \% \mathrm{O}_{2}$. The sputtering systems were mounted on conventional oil diffusion and mechanical pumps. A high-efficiency liquid nitrogen cold trap was used between the diffusion pump and the chamber to routinely attain pressures before deposition of $10^{-7}$ Torr. A variable orifice was used between the diffusion pump and the mechanical pump to throttle the flow of sputtering gases without reducing the $\mathrm{H}_{2} \mathrm{O}$ pumping speed of the cold trap. The orifice conductance was $\sim 201 / \mathrm{s}$ and the system throughput $\sim 0.4 \mathrm{Torr} 1 / \mathrm{s}$.

\section{Substrate Preparation}

Substrates were cleaned in two different ways. The first method, designated $D$ in this report, involved simple scrubbing with liquid detergent and rinsing in deionized water. The second method, designated $D+S$, consisted of detergent scrubbing followed by cleaning with a high-pressure (3000 psi) spray of deionized water in commercially-available equipment. 


\section{Coating Designs}

A11 single layers were made in thicknesses of $\lambda / 2,3 \lambda / 2$ and $2 \lambda$, so that the coating/substrate transmission at $248 \mathrm{~nm}$ was that of the substrate minus any absorption and scattering. High reflectors were all of the design $L L(H L)^{m} H L L$ where each layer is $\lambda / 4, \mathrm{~L}$ is always $\mathrm{SiO}_{2}$, and $\mathrm{H}$ is either $\mathrm{Al}_{2} \mathrm{O}_{3}, \mathrm{Y}_{2} \mathrm{O}_{3}$ or $\mathrm{HfO}_{2}$. The number of coating pairs $\mathrm{m}$ for $\mathrm{HfO}_{2}$ and $\mathrm{Y}_{2} \mathrm{O}_{3}$ was selected to yield a reflectivity of $99.9 \%$, assuming no absorption or scattering losses. The number of coating pairs for $\mathrm{Al}_{2} \mathrm{O}_{3}$ was selected to yield a reflectivity of $99.2 \%$ to avoid very thick coatings which might scatter in the ultraviolet. For $\mathrm{HfO}_{2}, \mathrm{Y}_{2} \mathrm{O}_{3}$ and $\mathrm{Al}_{2} \mathrm{O}_{3} \mathrm{~m}=6,10$ and 19 , respectively. $\mathrm{A} \lambda / 2 \mathrm{SiO}_{2}$ overiayer and underlayer, designated LL above, were used with each high reflector but not with the single layers.

In some preliminary work not described elsewhere in this report, a 2:1 high reflector design of the form $\left(H^{\prime} L^{\prime}\right)^{m} H^{\prime}$, where $H^{\prime}=\lambda / 6$ and $L^{\prime}=\lambda / 3$ near $496 \mathrm{~nm}$ and $\mathrm{m}=12$, was tried for $\mathrm{Y}_{2} \mathrm{O}_{3} / \mathrm{SiO}_{2}$ to simplify monitoring of layer thicknesses. However, the increased absorption and scattering associated with the thicker layers in this design caused lower reflectivities for the secondorder peak at $248 \mathrm{~nm}$ that obtained with the first-order peak for the $\lambda / 4$ stack described above.

\section{Coating Deposition}

Complete deposition conditions for each coating damage tested are listed in Table 2. Before each deposition was started, each target was sputter cleaned onto the rotatable shutter for 60 minutes under the same conditions used for deposition. This procedure removed any contamination from the target surface and also greatly reduced the residual pressure of $\mathrm{H}_{2} \mathrm{O}, \mathrm{O}_{2}$ and $\mathrm{N}_{2}$ in the chamber through the gettering action of the strongly reactive metals $\mathrm{Si}, \mathrm{Al}, \mathrm{Hf}$ and $\mathrm{Y}$. Between layers of a stack, target power was momentarily reduced to zero, the substrate table was manually rotated to the next target, and target power was again increased to its desired value. Any tuning of the rf matching network required was done manually in the first 15 seconds of each layer deposition. Coating thickness was monitored by the product of target power and elapsed time. This procedure is quite adequate for sputtering, as opposed to evaporation, 
because in sputtering the deposition rate is linearly proportional to the target power and reproducible to within a few percent from deposition to deposition.

\section{Coating Characterization}

A11 optical measurements were made with a double-beam, double-monochromator spectrophotometer operating for wavelengths of 200 to $2900 \mathrm{~nm}$. Coating transmission accuracy is $\pm 0.2 \%$. Reflectivity accuracy at $248 \mathrm{~nm}$ is $\pm 1 \%$. Wavelength accuracy is $\pm 1 \mathrm{~nm}$. The reflectivity of each mirror damage tested was measured at nine points arranged in an " $x$ " pattern across the face of the substrate. A similar procedure was used for measurement of the tuned wavelength of a mirror.

Crystal structure, grain size and preferred orientation data were obtained using standard $x$-ray diffractometer techniques which involve analysis of peak location, peak strength and peak broadening. Diffractometer scans on thin optical coatings required long counting times and also digital data storage, manipulation and analysis. Data were collected at 0.05 degree intervals in the scattering angle $2 \theta$ with 80 s counting periods.

Coating surface topography was examined using Nomarski microscopy and SEM. Purity of selected coatings and a 11 sputtering targets was verified by $x$-ray fluorescence examination, using $x$-ray excitation for targets and electron-beam excitation for coatings.

RESULTS

\section{Laser Damage Thresholds}

A11 laser damage data accumulated throughout this work are listed in Table 3 and plotted in Figure 2. In Table 3, coatings are identified by LLNL substrate number, LLNL damage testing number and PNL coating number, and are 1 isted in the same order as in Table 2 which contains complete deposition condition information. Included for easy comparison with the damage threshold numbers are the coating material and design, any unusual deposition condition, tuned wavelength, mirror reflectivity, substrate material and polish, and the beam polarization for $10^{\circ}$ incidence. Table 3 also contains comments made by LLNL damage testing personnel 
concerning the overall appearance of the coatings and a ranking of their "cleanliness". Figure 2 plots damage threshold as a function of coating material and coating design, and also displays average thresholds for each design.

The highest damage thresholds were observed for $\mathrm{Al}_{2} \mathrm{O}_{3} / \mathrm{SiO}_{2}$ with all four mirrors between 2.0 and $2.3 \mathrm{~J} / \mathrm{cm}^{2}$. One $\mathrm{HfO}_{2} / \mathrm{SiO}_{2}$ mirror damaged at $2.1 \mathrm{~J} / \mathrm{cm}^{2}$, but two others damaged at 1.0 and $0.9 \mathrm{~J} / \mathrm{cm}^{2}$. Al1 five $\mathrm{Y}_{2} \mathrm{O}_{3} / \mathrm{SiO}_{2}$ mirrors damaged between 0.4 and $0.7 \mathrm{~J} / \mathrm{cm}^{2}$.

In general the reflectors yielded damage thresholds comparable to the single-layer coatings of the same material. This result is most easily seen in Figure 2. Reflectors averaged $2.2 \mathrm{~J} / \mathrm{cm}^{2}$ for $\mathrm{Al}_{2} \mathrm{O}_{3} / \mathrm{SiO}_{2}, 1.3 \mathrm{~J} / \mathrm{cm}^{2}$ for $\mathrm{HfO}_{2} / \mathrm{SiO}_{2}$ and $0.6 \mathrm{~J} / \mathrm{cm}^{2}$ for $\mathrm{Y}_{2} \mathrm{O}_{3} / \mathrm{SiO}_{2}$. Single-layer thresholds were $2.0,0.6$ and 0.6 $\mathrm{J} / \mathrm{cm}^{2}$, respectively. It may be important to note however that, inadvertently, a 11 reflectors were deposited on Bk-7 glass and all single layers on fused silica. The damage thresholds do not increase in proportion to the optical band gaps or in inverse proportion to the refractive indices of these three materials, al though highest thresholds were obtained for $\mathrm{Al}_{2} \mathrm{O}_{3}$ which does have the highest band gap and lowest refractive index.

No obvious correlation exists between damage thresholds and the reflectivities of the mirrors, as shown in Figure 3 , although the results are not inconsistent with a correlation. $\mathrm{Al}_{2} \mathrm{O}_{3} / \mathrm{SiO}_{2}$, with the highest thresholds, had intermediate reflectivities of $80-83 \%$. $\mathrm{HfO}_{2} / \mathrm{SiO}_{2}$, with the highest reflectivities of $94-96 \%$, had intermediate thresholds. For $\mathrm{Y}_{2} \mathrm{O}_{3} / \mathrm{SiO}_{2}$, where reflectivities varied over a wide range from 67 to $80 \%$, there also was no correlation with damage threshold.

No obvious correlation exists between damage threshold and tuned wavelength, as shown in Figure 4. This is particularly clear for $\mathrm{Y}_{2} \mathrm{O}_{3} / \mathrm{SiO}_{2}$ mirrors for which tuned wavelengths range from 244 to $280 \mathrm{~nm}$.

For the single-layer coatings, $\mathrm{Al}_{2} \mathrm{O}_{3}$ damaged at higher fluences when deposited with $50 \% \mathrm{O}_{2}$ in the sputtering gas than with $15 \% \mathrm{O}_{2}$. In fact, the two $\lambda / 2 \mathrm{Al}_{2} \mathrm{O}_{3}$ coatings made with high $\mathrm{O}_{2}$ partial pressure exhibited the highest thresholds of any single or multilayer coatings examined in this work. These thresholds were 2.6 and $3.2 \mathrm{~J} / \mathrm{cm}^{2}$. Higher $0_{2}$ partial pressure was therefore used for all subsequent multilayer depositions involving $\mathrm{Al}_{2} \mathrm{O}_{3}$. 
There is no obvious correlation between the thickness of the single layers and their thresholds, as shown in Figure 5. For $\mathrm{Al}_{2} \mathrm{O}_{3}$, thresholds increase slightly with coating thickness for $15 \% \mathrm{O}_{2}$ coatings and decrease for $50 \% \mathrm{O}_{2}$. For $\mathrm{HfO}_{2}$, thresholds increase or remain constant with increasing thickness. For $\mathrm{Y}_{2} \mathrm{O}_{3}$, thresholds decrease with increasing thickness.

Nearly identical results were obtained for $\mathrm{Al}_{2} \mathrm{O}_{3}$ single layers with the two substrate cleaning techniques $D$ and $D+S$, for both $0_{2}$ partial pressures and for all three thicknesses involved. These results are also shown in Figure 5. Hence high-pressure water-spray cleaning does not appear to influence, and in particular does not decrease, damage thresholds as popularly believed. Note, however, that comparisons of the two cleaning techniques were made only for silica substrates and not Bk-7 glass.

No correlation is clearly apparent in Table 3 between damage threshold and substrate polishing technique, even though coatings were made and tested on (1) the front surface of conventionally polished substrates, (2) the rear surface of conventionally polished substrates, and (3) OCLI superpolished substrates.

No difference is obvious in Table 3 between results for $p$ and $s$ beam polarizations.

Finaily, there does appear to be a correlation between damage threshold and the "cleanliness" ranking of the coatings. Here "cleanliness" is ranked from 0 (clean) to 3 (very dirty) by LLNL as a measure of the density of "submicronsized artifacts" in the coatings. As shown in Figure 6, thresholds are grouped primarily by coating material rather than by cleanliness. But, within each coating material group, slightly higher thresholds are obtained for lower "cleanliness" rankings.

\section{Mirror Reflectivities}

Mirror reflectivities achieved with high reflector designs for the three coating materials combinations are displayed as a function of tuned wavelength in Figures 7,8 and 9 for $\mathrm{Al}_{2} \mathrm{O}_{3} / \mathrm{SiO}_{2}, \mathrm{HfO}_{2} / \mathrm{SiO}_{2}$ and $\mathrm{Y}_{2} \mathrm{O}_{3} / \mathrm{SiO}_{2}$, respectively. Included in these figures are mirrors made on LLNL substrates for damage testing and mirrors made on PNL substrates for materials characterization. Coating identification numbers appearing in the figures are PNL coating numbers which 
can be cross referenced to LLNL substrate or damage test numbers through the use of Table 2 or 3 . For most coatings, nine points are plotted for measurements made in an " $x$ " pattern across the face of the substrate. For some coatings, fewer measurements were made. The points thus plotted show two dependences: (1) the overall dependence of reflectivity on tuned wavelength for a particular pair of materials and (2) the variation of reflectivity across the face of individual coatings.

For $\mathrm{Al}_{2} \mathrm{O}_{3} / \mathrm{SiO}_{2}$, reflectivities vary from as $10 \mathrm{~W}$ as $74 \%$ to as high as $91 \%$ with a median value of $81 \%$. The reflectivity is essentially independent of the tuned wavelength. For most individual coatings, the variation across the face of the substrate is $\pm 2 \%$ in reflectivity and $\pm 2 \%$ in tuned wavelength. Both variations are close to the precision limits of the spectrophotometer for wavelengths near $248 \mathrm{~nm}$ and thus may not be statistically significant.

For $\mathrm{HfO}_{2} / \mathrm{SiO}_{2}$, similar results are obtained except that the reflectivities are higher. Reflectivities range from 88 to $100 \%$ with a median value of $95 \%$. The reflectivity is independent of wavelength for wavelengths greater than 220 $\mathrm{nm}$, but for shorter wavelengths falls off rapidly. For most individual coatings, the variation across the face of the substrate is $\pm 2 \%$ in reflectivity and $\pm 1 \%$ in tuned wavelength. The spread in reflectivity values is largest for wavelengths less than $220 \mathrm{~nm}$, as shown for coating \#13I in Figure 8, and the reflectivity is lowest at the substrate center and highest at the perimeter.

For $\mathrm{Y}_{2} \mathrm{O}_{3} / \mathrm{SiO}_{2}$, however, the results are quite different. Reflectivities as high as $85 \%$ are obtained for tuned wavelengths near $285 \mathrm{~nm}$, but the reflectivity drops off rapidly for shorter wavelengths to $55 \%$ at $240 \mathrm{~nm}$. Also note that, although the variation in tuned wavelength across the face of an individual coating is usually only $\pm 2 \%$, the variation in reflectivity is typically $\pm 6 \%$ or larger. Finally, it is important to point out that the nine-point reflectivity profiling always showed highest reflectivity and longest tuned wavelength near the perimeter of the substrate, monotonically decreasing to the lowest reflectivity and shortest tuned wavelength near the substrate center. 
The measured spectral dependence of the reflectivity is shown in Figures 10, 11 and 12 for some of the best $\mathrm{Al}_{2} \mathrm{O}_{3} / \mathrm{SiO}_{2}, \mathrm{HfO}_{2} / \mathrm{SiO}_{2}$ and $\mathrm{Y}_{2} \mathrm{O}_{3} / \mathrm{SiO}_{2}$ mirrors, respectively. Shown for comparison is the reflectivity spectrum for each coating combination calculated to include refractive index dispersion for each material. The large differences in the band width of the high reflectance region for the three combinations are due to differences in refractive index contrast or ratio. Taking into account the peak reflectance, the band width of the high reflectance region and the "squareness" of the high reflectance region, the $\mathrm{HfO}_{2} / \mathrm{SiO}_{2}$ combination is by far the best to date. Second best is the $\mathrm{Al}_{2} \mathrm{O}_{3} / \mathrm{SiO}_{2}$ combination. The $\mathrm{Y}_{2} \mathrm{O}_{3} / \mathrm{SiO}_{2}$ combination is very discouraging. The differences between the calculated and measured curves for high reflectors, in general, can be due to absorption, scattering, layer thickness variations and refractive index variations. Layer thickness variations were ruled out for this work by separate measurements and Monte Carlo computer calculations. Refractive index variations and absorption/scattering will be described in the Discussion section of this report.

\section{Single Layer Optical Properties}

Fabrication of multilayer mirrors in the ultraviolet requires very close attention to the onset of the absorption edge of each coating material, enhanced scattering effects because of the very short wavelengths, and refractive index dispersion near the absorption edge. The absorption edge for each material can be seen in Figure 13 which displays typical spectrophotometer data for single layer coatings of $\mathrm{HfO}_{2}, \mathrm{Y}_{2} \mathrm{O}_{3}$ and $\mathrm{Al}_{2} \mathrm{O}_{3}$ on fused silica substrates. The transmission of the bare substrate used for each coating is also shown. Except for the $\mathrm{SiO}_{2}$ coatings which transmit very well down to and below $200 \mathrm{~nm}, \mathrm{Al}_{2} \mathrm{O}_{3}$ by far has the shortest wavelength absorption edge. The actual edge for the $\mathrm{Al}_{2} \mathrm{O}_{3}$ coating is probably below $200 \mathrm{~nm}$, but appears to be at a higher wavelength in Figure 13 because of absorption by the $\mathrm{SiO}_{2}$ substrate. Suprasil type silica should be used for future ultraviolet work rather than the type IR-12 used for these measurements. The absorption edges for $\mathrm{Y}_{2} \mathrm{O}_{3}$ and $\mathrm{HfO}_{2}$ both are seen to be near $220 \mathrm{~nm}$. However, some transmission loss due to absorption and/or scattering is apparent for each material near the $248 \mathrm{~nm}$ wavelength of interest. 
Absorption and scattering losses for each coating material can be seen more clearly in Figures 14 through 17 which show the difference between coated and uncoated substrate transmission near $248 \mathrm{~nm}$ as a function of single-layer coating thickness. Data plotted here are taken from coatings on both PNL and LLNL substrates. The thickness corresponding to a quarter wavelength at $248 \mathrm{~nm}$ is also shown. These losses are due to both absorption and scattering, and separation of the contributions made by each is, in general, difficult. However, Figures 14 through 17 can be used to make rough estimates. For thin films which are polycrystalline (such as $\mathrm{HfO}_{2}, \mathrm{Y}_{2} \mathrm{O}_{3}$ and $\mathrm{Al}_{2} \mathrm{O}_{3}$ as shown in the next section) both absorption and scattering losses are expected to increase with thickness. For glassy films (such as $\mathrm{SiO}_{2}$ ) only the absorption loss is expected to increase significantly with thickness. The transmission loss $\Delta T$ due to absorption, in general, increases as

$$
\Delta T \sim\left(1-e^{-\beta x}\right),
$$

where $\beta$ is the absorption coefficient and $x$ the coating thickness. For thin films, the loss is approximatley given by

$$
\Delta T \sim \beta x,
$$

where $\beta$ is the slope of a transmission loss versus thickness plot. Thus for the case of $\mathrm{SiO}_{2}$, where scattering is assumed to be negligible, a least squares straight-line fit to the data of Figure 17 yields $\beta(248 \mathrm{~nm})=210 \mathrm{~cm}^{-1}$. Upper limits for $\beta(248 \mathrm{~nm})$ for $\mathrm{HfO}_{2}, \mathrm{Y}_{2} \mathrm{O}_{3}$ and $\mathrm{Al}_{2} \mathrm{O}_{3}$ can be similarly deduced from Figures 14 through 17 if it is assumed that scattering does not increase with thickness. The results 1 isted in Table 4 are 2600,1770 and $3900 \mathrm{~cm}^{-1}$ for $\mathrm{Al}_{2} \mathrm{O}_{3}, \mathrm{Y}_{2} \mathrm{O}_{3}$ and $\mathrm{HfO}_{2}$, respectively. Note that these coefficients are 10 times larger than $\beta$ for $\mathrm{SiO}_{2}$, suggesting that, rather than being insignificantly sma11, the scattering contribution to the transmission loss is in fact much larger than the absorption contribution. However, the upper limits calculated for $\beta$ of these three polycrystalline coatings will be useful in the Discussion section of this report. Also shown in Table 4 for each coating material is the extinction coefficient or imaginary part of the refractive index $k$ defined as

$$
k=\beta \lambda / 4 \pi \text {. }
$$

Note that like $\beta, \mathrm{k}$ for $\mathrm{HfO}_{2}, \mathrm{Y}_{2} \mathrm{O}_{3}$ and $\mathrm{Al}_{2} \mathrm{O}_{3}$ is an upper limit value. 
The refractive index for each coating material can be deduced from the amplitude of oscillation for transmission data such as that displayed in Figure 13. Refractive index dispersion can be calculated from the positions of the extrema. Figure 18 shows the variation of the refractive index with wavelength for each coating material, and Table 5 lists fit parameters for a least squares analysis of data taken for several coatings of each material. The difference in absorption edge between $\mathrm{SiO}_{2}$ and $\mathrm{Al}_{2} \mathrm{O}_{3}$ compared to $\mathrm{Y}_{2} \mathrm{O}_{3}$ and $\mathrm{HfO}_{2}$ is obvious from the rate of variation of the index in Figure 18. The refractive index for each coating material can be calculated at any wavelength from the fit parameters and the equation given in Table 5. Column 5 of the table 7 ists the index at $248 \mathrm{~nm}$. Column 4 is a good estimate of the long wavelength $(\sim 1000 \mathrm{~nm})$ index.

\section{Coating Microstructural Properties}

Coating microstructural properties deduced from $x$-ray diffractometer data are summarized for all four materials in Table 6 . Properties deduced include crystal structure, grain size and preferred crystallographic orientation of grains relative to the substrate surface.

$\mathrm{SiO}_{2}$ coatings made in this work were glassy or amorphous, and exhibited no long range order. Grain size and preferred orientation have little meaning in this 1 imit.

$\mathrm{Al}_{2} \mathrm{O}_{3}$ coatings made in this work crystallized in the cubic $(\gamma)$ structure with grain sizes of 30 to $100 \AA$. Orientation of the grains was random.

$\mathrm{Y}_{2} \mathrm{O}_{3}$ coatings had the largest grain sizes of all materials examined in this work, and ranged from 340 to $540 \mathrm{~A}$. The grains were very strongly oriented with the (222) crystallographic planes parallel to the substrate surface. The ratio of the area under the (222) peak to the sum of the areas for al1 the diffraction peaks was typically 0.90 .

$\mathrm{HfO}_{2}$ coatings crystallized in the monoclinic structure with grain sizes of 100 to $300 \AA$. The preferred orientation was (11T), and was strong with a peak area ratio typically of 0.65 . 
DISCUSSION

\section{Overview}

From the results presented in the previous section it seems clear that the principal factor limiting the damage thresholds observed for mirrors made to date is their relatively low reflectivity. It is well known that reflectivity losses in all-dielectric mirrors are due to four factors: (1) absorption, (2) scattering, (3) layer thickness errors, and (4) refractive index errors due to layer-to-layer variation or dispersion. With the extensive characterization data accumulated in this work, each of these factors can be related to either the optical or physical properties of the individual coating materials or to the process used to deposit them. In the paragraphs that follow, the loss in reflectivity due to each of these factors is estimated in magnitude for each coating material combination examined, and the coating properties or deposition process features responsible for each factor is discussed. In general, it is found that the relative size of each factor for each material combination is different, so that each combination will require individual optimization in any future work contemplated.

Table 7 summarizes the reflectivities achieved for typical $\mathrm{HfO}_{2} / \mathrm{SiO}_{2}$, $\mathrm{Y}_{2} \mathrm{O}_{3} / \mathrm{SiO}_{2}$ and $\mathrm{Al}_{2} \mathrm{O}_{3} / \mathrm{SiO}_{2}$ mirrors, and $\mathrm{lis}$ ts the estimated reflectivity losses due to transmission, absorption and scattering as a function of the tuned wavelength of the mirror. Both good and bad reflectors are included to give a better overall picture. The transmission losses were made by direct spectrophotometer measurements for mirrors made on fused silica substrates which transmit well near $248 \mathrm{~nm}$. Losses due to transmission are primarily caused by thickness and refractive index errors since all reflectors were made with a sufficient number of layers to limit transmission to $0.1 \%$ for $\mathrm{HfO}_{2} / \mathrm{SiO}_{2}$ and $\mathrm{Y}_{2} \mathrm{O}_{3} / \mathrm{SiO}_{2}$ and to $0.8 \%$ for $\mathrm{Al}_{2} \mathrm{O}_{3} / \mathrm{SiO}_{2}$. The combined absorption plus scattering loss labeled A+S in column 6 of Table 7 was calculated by summing the reflectivity and transmission measured at the tuned wavelength and subtracting from $100 \%$. The absorption loss labeled A in column 7 was calculated from the extinction coefficients $k$ of Table 4 and the refractive indices $n$ of Table 5 using the relation $(1)$

$$
A=-\delta R=\frac{2 \pi}{n_{H}^{2}-n_{L}^{2}}\left(k_{H}+k_{L}\right) .
$$


For each calculated $A$ loss, $L$ refers to $\mathrm{SiO}_{2}$ and $\mathrm{H}$ to either $\mathrm{HfO}_{2}, \mathrm{Y}_{2} \mathrm{O}_{3}$ or $\mathrm{Al}_{2} \mathrm{O}_{3}$. Although the $k$ values of Table 4 are upper limits, their use allows calculation of an upper limit for $A$ so that the losses due to absorption and scattering can be separated for complete analysis of the reflectors.

$$
\underline{\mathrm{HfO}_{2} / \mathrm{SiO}_{2} \text { Mirrors }}
$$

Best reflectors to date were obtained for $\mathrm{HfO}_{2} / \mathrm{SiO}_{2}$. As shown in Table 7 , reflectivities in excess of $99 \%$ were obtained at some points on some mirrors. At these points, the principal losses were 0.6 to $0.9 \%$ and were due to mirror transmission, indicating that slightly better control of layer thickness and/or refractive index is needed to attain the $0.1 \%$ minimum theoretical loss. The index dispersion data of Figure 18 and our experience with the degree of thickness control achievable with the sputtering process suggest that this small problem is due mainly to accounting for the rapid wavelength variation of the refractive index with insufficient accuracy. The large dispersion in the index of $\mathrm{HfO}_{2}$ is due to its relatively low optical band gap. The difficulty it presents must be traded off against the advantages of the high refractive index of this material. Note that absorption losses at the high reflectivity regions were at most 0.1 to $0.2 \%$, indicating that the absorption edge of $\mathrm{HfO}_{2}$ is sufficiently low in wavelength for use of this material at $248 \mathrm{~nm}$. At some regions of $\mathrm{HfO}_{2} / \mathrm{SiO}_{2}$ mirrors, reflectivities were only $\sim 95 \%$. As shown in Table $7, \cdot$ the transmission loss at these points was $1 \%$ and about the same as in the high reflectivity regions of the mirrors. However, the absorption plus scattering loss was $3.6 \%$. Using the calculated upper limit of $1.5 \%$ for absorption loss, most $(2.1 \%)$ of the reflectivity loss is seen to arise from scattering. Scattering losses are caused by coating surface roughness and by nonhomogeneous coating microstructure due to columnar grains or growth features.

It is interesting to note that with $\mathrm{HfO}_{2} / \mathrm{SiO}_{2}$, and with $\mathrm{Y}_{2} \mathrm{O}_{3} / \mathrm{SiO}_{2}$ and $\mathrm{Al}_{2} \mathrm{O}_{3} / \mathrm{SiO}_{2}$ as will be discussed later, the high reflectivity regions were almost always near the perimeter of the two-inch substrates and the lower reflectivity regions near the central 1/2 inch. An example of a typical reflectivity and tuned-wavelength profile is shown in Figure 19. The cause of the increased surface roughness near the center of the mirrors is not understood. A similar center roughening phenomenon was observed several times for single-layer $\mathrm{HfO}_{2}$ coatings deposited at high gas pressures. The increased roughness appears to be 
an artifact of the sputter deposition of these particular materials and may be due to negative ion effects during deposition in the plasma. Further discussion of negative ion effects is beyond the scope of this report.

One general feature of the $\mathrm{HfO}_{2}$ coatings that also deserves mention is the grain size. As shown in Table 6, grain sizes ranged from 100 to $300 \AA$. Although scattering losses due to surface roughness were not observed to be large, with the exception of the peculiar phenomenon mentioned above for the central region of the mirrors, future work on $\mathrm{HfO}_{2}$ coatings for ultraviolet applications should address further reduction of grain size through deposition parameter optimization since ideal coating surface topographies are obtained with the smallest grain sizes. Data supporting this conclusion are shown in Figure 20 which displays the grain-size dependence of the scattering loss at $248 \mathrm{~nm}$ for single-layer coatings with near-equal thicknesses of approximately $2500 \AA$.

\section{$\underline{\mathrm{Y}_{2} \mathrm{O}_{3} / \mathrm{SiO}_{2} \text { Mirrors }}$}

The least encouraging results to date were obtained for $\mathrm{Y}_{2} \mathrm{O}_{3} / \mathrm{SiO}_{2}$. As shown in Table 7 and Figure 9, reflectivities ranged from 55 to $83 \%$ and were strongly dependent on tuned wavelength. Highest reflectivities occurred for the longest tuned wavelengths. The poor performance of $\mathrm{Y}_{2} \mathrm{O}_{3} / \mathrm{SiO}_{2}$ reflectors is difficult to understand because the single-layer $\mathrm{Y}_{2} \mathrm{O}_{3}$ coatings exhibited excellent optical properties. The data of Figure 13 show very little loss near 248 $\mathrm{nm}$, and the maximum $248 \mathrm{~nm}$ extinction coefficient in Table 4 is the lowest of the three high index materials. The absorption edge shown in Figure 13, however, is slightly longer in wavelength than expected and even falls at longer wavelengths than $\mathrm{HfO}_{2}$. Largest reflectivity losses come from absorption plus scattering, as shown in Table 7 , and range from 13 to $32 \%$. The maximum calculated absorption loss for an $\mathrm{Y}_{2} \mathrm{O}_{3} / \mathrm{SiO}_{2}$ reflector is $1.0 \%$, suggesting that scattering is the principal problem. The transmission losses shown in Table 7 are also very large, but probably result from the large scattering losses rather than from thickness or index errors. A contribution due to refractive index errors associated with the large dispersion of $\mathrm{Y}_{2} \mathrm{O}_{3}$, however, should not be completely ruled out. 
There are several apparent explanations for the large scattering losses. First the grain sizes shown in Table 6 for $\mathrm{Y}_{2} \mathrm{O}_{3}$ coatings are 340 to $540 \AA$. These grains are very large for ultraviolet applications and almost certainly result in extreme surface roughness. The very strong preferred crystallographic orientation of the $\mathrm{Y}_{2} \mathrm{O}_{3}$ coatings suggests pronounced columnar microstructure with surface roughness caused by the rounded caps of the columnar grains. In fact, some SEM surface micrographs such as that displayed in Figure 21 for a 23-1ayer high reflector show the columnar caps or "cobblestone effect" very clearly. Secondly, the possibility of a metallurgical reaction between the $\mathrm{SiO}_{2}$ and $\mathrm{Y}_{2} \mathrm{O}_{3}$ layers during deposition is suggested by the apparent difference in optical properties for single layers and multilayer stacks. Several Y-Si compounds exist in the published phase diagrams ${ }^{(2)}$ and may be thermodynamically likely under the conditions of coating deposition. Finally, the center roughening phenomenon described for $\mathrm{HfO}_{2} / \mathrm{SiO}_{2}$ was equally apparent in the $\mathrm{Y}_{2} \mathrm{O}_{3} / \mathrm{SiO}_{2}$ mirrors.

\section{$\underline{\mathrm{Al}_{2} \mathrm{O}_{3} / \mathrm{SiO}_{2} \text { Mirrors }}$}

Reflectivities for $\mathrm{Al}_{2} \mathrm{O}_{3} / \mathrm{SiO}_{2}$ ranged from 74 to $90 \%$, and were typically 80 to $88 \%$. Results shown in Table 7 for three of the best $\mathrm{Al}_{2} \mathrm{O}_{3} / \mathrm{SiO}_{2}$ mirrors indicate that transmission, absorption and scattering losses were equally important and were each typically 5\%. Recal1, however, that the absorption loss is a calculated maximum value so that the actual scattering loss may have been greater than $5 \%$ but less than 10\%. Most of the large transmission loss is believed to result from the smallness of the refractive index contrast between $\mathrm{Al}_{2} \mathrm{O}_{3}$ and $\mathrm{SiO}_{2}$ which results in a very narrow reflectance peak (see Fig. 10) and requires unusually tight tolerances on index reproducibility from layer to layer and run to run. Recall that $0.8 \%$ of the transmission loss is expected since the $\mathrm{Al}_{2} \mathrm{O}_{3} / \mathrm{SiO}_{2}$ mirrors were designed for only $99.2 \%$ reflectivity. The scattering loss most likely results from the large number of coating layers required for $\mathrm{Al}_{2} \mathrm{O}_{3} / \mathrm{SiO}_{2}$ and the larger thickness of each layer for these low index materials. In fact, the $\mathrm{Al}_{2} \mathrm{O}_{3} / \mathrm{SiO}_{2}$ reflector is $1.68 \mu \mathrm{m}$ thick, which is almost twice the $0.898 \mu \mathrm{m}$ thickness of the $\mathrm{Y}_{2} \mathrm{O}_{3} / \mathrm{SiO}_{2}$ reflector and almost three times the $0.599 \mu \mathrm{m}$ thickness of the $\mathrm{HfO}_{2} / \mathrm{SiO}_{2}$ reflector. This increase in thickness offsets the surfaceroughness benefits of the very fine grain size of the $\mathrm{Al}_{2} \mathrm{O}_{3}$ coatings, shown in Table 6 to be only 30 to $100 \mathrm{~A}$. Future work with $\mathrm{Al}_{2} \mathrm{O}_{3} / \mathrm{SiO}_{2}$ should examine 
tradeoffs between reflectivity and scattering for stacks with different numbers of coating pairs. The actual absorption loss in the $\mathrm{Al}_{2} \mathrm{O}_{3} / \mathrm{SiO}_{2}$ stack is believed to be significantly less than $5 \%$ because of the large band gaps of these materials. Finally, some reduction of reflectivity near the center of the two-inch substrates . was also noticed for $\mathrm{Al}_{2} \mathrm{O}_{3} / \mathrm{SiO}_{2}$, but the effect appeared to be smaller than for $\mathrm{HfO}_{2} / \mathrm{SiO}_{2}$ and $\mathrm{Y}_{2} \mathrm{O}_{3} / \mathrm{SiO}_{2}$.

\section{CONCLUSIONS}

Laser damage thresholds of 2.0 to $2.3 \mathrm{~J} / \mathrm{cm}^{2}$ for $20 \mathrm{~ns}$ pulses at $248 \mathrm{~nm}$ were consistently demonstrated for al1-dielectric reflectors made with a 39-1ayer quarter-wave stack of $\mathrm{Al}_{2} \mathrm{O}_{3} / \mathrm{SiO}_{2}$ plus a half-wave $\mathrm{SiO}_{2}$ underlayer and a halfwave $\mathrm{SiO}_{2}$ overlayer. A.threshold of $2.1 \mathrm{~J} / \mathrm{cm}^{2}$ was achieved for one 13-1ayer stack of $\mathrm{HfO}_{2} / \mathrm{SiO}_{2}$, but two other identical reflectors damaged at 0.9 and 1.0 $\mathrm{J} / \mathrm{cm}^{2}$. Thresholds for $21-1$ ayer $\mathrm{Y}_{2} \mathrm{O}_{3} / \mathrm{SiO}_{2}$ reflectors ranged from 0.3 to $1.1 \mathrm{~J} / \mathrm{cm}^{2}$. The $\mathrm{HfO}_{2} / \mathrm{SiO}_{2}$ and $\mathrm{Y}_{2} \mathrm{O}_{3} / \mathrm{SiO}_{2}$ reflectors also employed half-wave $\mathrm{SiO}_{2}$ underlayers and overlayers. Although short of the $5 \mathrm{~J} / \mathrm{cm}^{2}$ goal of this work, optimization of the deposition of these coating materials to reduce surface roughness and scattering promises to yield higher thresholds.

Point-to-point average reflectivities of $94-96 \%$ were achieved for $\mathrm{HfO}_{2} / \mathrm{SiO}_{2}$ reflectors, with $99-100 \%$ reflectivities at some points. $\mathrm{Al}_{2} \mathrm{O}_{3} / \mathrm{SiO}_{2}$ mirrors averaged $80-83 \%$ with some $90 \%$ points. $\mathrm{Y}_{2} \mathrm{O}_{3} / \mathrm{SiO}_{2}$ reflectors averaged $62-80 \%$ with some $85 \%$ points. The principal cause of reduced reflectivity in most cases was scattering from surface roughness. The easiest reflectors to make were the $\mathrm{HfO}_{2} / \mathrm{SiO}_{2}$ because the high refractive index contrast of this combination requires fewer and thinner coating layers and results in a broad reflectance maximum. $\mathrm{Al}_{2} \mathrm{O}_{3} / \mathrm{SiO}_{2}$ mirrors were the most difficult to make because of low refractive index contrast.

Damage threshold did not correlate with the mirror reflectivity, al though it seems likely that improvement of the mirror reflectivity by reduction of obvious coating surface roughness would produce the most immediate improvement in damage resistance. Damage thresholds for reflectors were similar to those obtained with single layers of the high-index material, supporting the conclusion stated in the previous sentence. No clear evidence for damage initiation by 
two-photon processes was obtained from the dependence of threshold on the absorption edges of the three high-index materials, al though $\mathrm{Al}_{2} \mathrm{O}_{3}$ did consistently exhibit the highest damage resistance. Damage resistance did not appear to depend on: (1) single-layer thickness, (2) stack tuned wavelength, (3) laser beam polarization, (4) substrate polishing technique, or (5) substrate cleaning technique. It did appear, however, that significant improvement in damage resistance could come from increased attention to coating cleanliness.

$\mathrm{SiO}_{2}, \mathrm{Al}_{2} \mathrm{O}_{3}, \mathrm{Y}_{2} \mathrm{O}_{3}$ and $\mathrm{HfO}_{2}$ all appear to be promising candidate materials for use at $248 \mathrm{~nm}$ wavelength. However, further optimization of coating properties is definitely necessary for the three high-index materials. $\mathrm{HfO}_{2}$ and $\mathrm{Y}_{2} \mathrm{O}_{3}$ must be deposited with finer grain sizes to reduce surface roughness. The peculiar center roughening phenomenon, which appears to be an artifact of the reactive sputter deposition of these materials, must be eliminated or minimized for $\mathrm{HfO}_{2}$, $\mathrm{Y}_{2} \mathrm{O}_{3}$ and $\mathrm{Al}_{2} \mathrm{O}_{3}$. The possibility of a metallurgical reaction between $\mathrm{Y}_{2} \mathrm{O}_{3}$ and $\mathrm{SiO}_{2}$ was suggested by the difference in optical properties for $\mathrm{Y}_{2} \mathrm{O}_{3}$ in single layers and $\mathrm{Y}_{2} \mathrm{O}_{3}$ in multilayer stacks with $\mathrm{SiO}_{2}$. Finally, the large coating thickness for $\mathrm{Al}_{2} \mathrm{O}_{3} / \mathrm{SiO}_{2}$ reflectors suggests study of the tradeoff between reflectivity and scattering as the number of coating pairs is varied.

The principal factor influencing the apparent ultraviolet absorption edge for each of $\mathrm{HfO}_{2}, \mathrm{Y}_{2} \mathrm{O}_{3}$ and $\mathrm{Al}_{2} \mathrm{O}_{3}$ was scattering due to coating surface roughness and large microstructural characteristics such as grain boundaries and columnar growth features. Scattering contributed by substrate roughness did not appear to be significant. The influence of absorption on the ultraviolet edge appeared to be small. Thus the level of stoichiometry and purity achieved appear to be adequate, and absorption due to intrinsic interband mechanisms does not appear to be important for any of these materials at $248 \mathrm{~nm}$.

Reactive sputter deposition appears to be a viable technique for fabricating al1-dielectric ultraviolet reflectors. A deposition parameter matrix study is, however, required to optimize coating microstructure and surface topography. Increased attention to coating thickness and index control from layer-to-layer and run-to-run also seems important for ultraviolet reflectors. Refinement of refractive index dispersion curves and their incorporation in multilayer coating designs is further needed. Finally, the level of cleanliness achieved in coating deposition and the care in handling of finished coatings require improvement. 
RECOMMENDATIONS FOR FUTURE STUDY

The most important area for future work is optimization of the microstructure and surface topography of the high-index materials $\mathrm{HfO}_{2}, \mathrm{Y}_{2} \mathrm{O}_{3}$ and $\mathrm{Al}_{2} \mathrm{O}_{3}$ to minimize reflectivity losses due to scattering and thus increase damage resistance. Such optimization should probably take the form of a deposition parameter matrix study and should include deposition rate, substrate temperature, sputtering gas pressure and substrate bias, all of which are known to influence coating microstructure in generally predictable ways. Appropriate coating evaluation techniques for the matrix study would include ultraviolet transmission measurements to determine the spectral dependence of the absorption edge, x-ray diffraction for grain size and orientation, and SEM for direct observation of surface features. Fabrication of multilayer stacks is also required to confirm coating improvements, and ultimately laser damage testing should be done.

Deposition experiments aimed at understanding the center roughening phenomenon should also be carried out. Particular attention should be paid to negative ion bombardment of the growing film in the sputtering plasma. These experiments should include examination of the influence of target voltage, sputtering gas pressure, substrate-target spacing, and off-axis placement of the substrate. Many aspects of the microstructure optimization and negative ion experiments can thus be investigated simultaneously.

Procedures resulting in tighter tolerances for layer thickness and refractive index control and monitoring with the sputtering process should be investigated, accompanied by Monte Carlo computer simulations to deduce the magnitude of expected effects. Refined refractive index dispersion curves are also needed, and an improved method for their incorporation into coating design should be developed.

Improvement in coating overall cleanliness is needed, and more attention should be paid to "cosmetics". Substrate cleaning procedures require further development, as do procedures for ensuring a cleaner vacuum deposition environment and more careful handling of completed coatings. 
For the $\mathrm{Al}_{2} \mathrm{O}_{3} / \mathrm{SiO}_{2}$ system, and possibly also $\mathrm{HfO}_{2} / \mathrm{SiO}_{2}$ and $\mathrm{Y}_{2} \mathrm{O}_{3} / \mathrm{SiO}_{2}$, the influence of the number of coating pairs on reflectivity improvement and scattering losses should be examined.

Finally, consideration should be given to expanding this effort to include improved compositions such as $\mathrm{Zr}$-free $\mathrm{HfO}_{2}$ or cubic-stabilized $\mathrm{HfO}_{2} \cdot 15$ mole \% $\mathrm{Y}_{2} \mathrm{O}_{3}$. These compositions may provide reduced absorption and scattering in the ultraviolet. New materials such as $\mathrm{MgAl}_{2} \mathrm{O}_{4}, \mathrm{Y}_{4} \mathrm{Al}_{2} \mathrm{O}_{9}$ and $\mathrm{Sc}_{2} \mathrm{O}_{3}$ should also be studied for use as the high-index material. Considerable data on the former two materials is already available ${ }^{(3)}$.

\section{ACKNOWLEDGEMENTS}

The authors would like to express their gratitude for the opportunity to work with the enthusiastic and capable staff at Lawrence Livermore National Laboratory on the development of damage resistant coatings for $\mathrm{Kr} * \mathrm{~F}$ lasers. In particular we thank Howard Lowdermilk, Dave Milam and Frank Rainer for making this work possible and for their time and efforts in testing and evaluating PNL coatings. We also thank Frank Rainer for his excellent summary chart and table which appear as Fig. 2 and Table 3 in this report. Finally, thanks are due to H.E. Kjarmo of PNL for SEM, $x$-ray diffraction and $x$-ray fluorescence analysis of the coatings. 


\section{REFERENCES}

1. J.A. Dobrowolski, in Handbook of Optics, edited by Walter G. Driscoll and Wi 11 iam Vaughan, (McGraw-Hi17, New York 1978), p. 8-65.

2. R.P. Elliott, Constitution of Binary Alloys, First Supplement, (McGraw-Hil1, New York 1965), p. 823.

3. W.T. Pawlewicz, D.D. Hays and P.M. Martin, Thin Solid Films 73 (1980) 169175. 
TABLE 1: Vendor, Fabrication Method and Purity of Sputtering Targets

\begin{tabular}{|c|c|c|c|}
\hline Material & Vendor & Fabrication Method & Purity \\
\hline $\mathrm{SiO}_{2}$ & Heraeus-Amersil, Inc. & $\begin{array}{l}\text { Suprasil } 2 \\
\text { Fused Silica }\end{array}$ & $99.9999 \%$ \\
\hline A1 & Materials Research Corp. & VP Metal plate & $99.995 \%$ \\
\hline $\mathrm{Y}_{2} \mathrm{O}_{3}$ & Cerac, Inc. & Hot-pressed powder & $99.999 \%$ \\
\hline $\mathrm{HfO}_{2}$ & Cerac, Inc. & Hot-pressed powder & $\begin{array}{l}99.95 \% \text {, except } \\
\text { for } 3 \text { mole \% } \\
\mathrm{ZrO}_{2}\end{array}$ \\
\hline
\end{tabular}


TABLE 2: Sputter Deposition Conditions

For All Coatings Damage Tested

\begin{tabular}{|c|c|c|c|c|c|c|c|c|c|c|}
\hline $\begin{array}{l}\text { LLNL } \\
\text { Substrate: }\end{array}$ & $\begin{array}{l}\text { Damage } \\
\text { Test \# }\end{array}$ & $\begin{array}{c}\text { PNL } \\
\text { Coating }\end{array}$ & $\begin{array}{l}\text { Coating } \\
\text { Material }\end{array}$ & $\begin{array}{l}\text { Coating } \\
\text { Design }\end{array}$ & $\begin{array}{l}\text { Substrate } \\
\text { Clean }\end{array}$ & $\begin{array}{l}\text { Target } \\
\text { Power(W) }\end{array}$ & $\begin{array}{c}\text { Target } \\
\text { Volts }\end{array}$ & $\begin{array}{l}\text { Gas } \\
\text { Pressure (mtorr) }\end{array}$ & $\underset{(\%)}{\operatorname{Ar} / 0_{2}}$ & $\begin{array}{l}\text { Deposjtion } \\
\text { Rate }(\AA / m i n)\end{array}$ \\
\hline $\begin{array}{l}804 \\
805 \\
81 ! \\
3 ! \\
379 \\
603 \\
307 \\
309\end{array}$ & $\begin{array}{l}14 \\
15 \\
18 \\
19 \\
12 \\
13 \\
16 \\
17\end{array}$ & $\begin{array}{ll}11 & \mathrm{D} \\
11 & \mathrm{E} \\
12 & \mathrm{D} \\
12 & \mathrm{E} \\
11 & \mathrm{~B} \\
11 & \mathrm{C} \\
12 & \mathrm{~B} \\
12 & \mathrm{C}\end{array}$ & $\begin{array}{c}\mathrm{Al}_{2} \mathrm{O}_{3} \\
" 1 \\
" \\
" \\
" \\
"\end{array}$ & $\begin{array}{c}\lambda / 2 \\
" \\
" \\
" \\
3 \lambda / 2 \\
" 1 \\
2 \lambda \\
"\end{array}$ & $\begin{array}{c}D+S \\
D \\
D \\
D+S \\
D \\
D+S \\
D \\
D+S\end{array}$ & $\begin{array}{c}600 \\
" 1 \\
" 1 \\
" 1 \\
" 1\end{array}$ & $\begin{array}{l}1550 \\
1450 \\
1400 \\
1400 \\
1550 \\
1550 \\
1400 \\
1350\end{array}$ & $\begin{array}{l}20 \\
" 1 \\
" \\
" \\
" \\
"\end{array}$ & $\begin{array}{c}85 / 15 \\
1 " \\
50 / 50 \\
1 " \\
85 / 15 \\
1 " \\
50 / 50 \\
11\end{array}$ & $\begin{array}{l}95.9 \\
10.2 \\
81.7 \\
80.9 \\
87.5 \\
85.5 \\
70.6 \\
70.1\end{array}$ \\
\hline $\begin{array}{l}2504 \\
2505 \\
2514 \\
2515\end{array}$ & $\begin{array}{l}95 \\
96 \\
97 \\
98\end{array}$ & $\begin{array}{ll}14 & \mathrm{C} \\
14 & \mathrm{D} \\
14 & \mathrm{H} \\
14 & \mathrm{I}\end{array}$ & $\begin{array}{c}\mathrm{Al}_{2} \mathrm{O}_{3} / \mathrm{SHO}_{2} \\
" \\
"\end{array}$ & $\begin{array}{c}\mathrm{SLL}(H L)^{19} \\
\text { " } \\
\text { " }\end{array}$ & $\begin{array}{l}D+S \\
D+S \\
D+S \\
D+S\end{array}$ & $\begin{array}{c}600 / 600 \\
" 1 \\
" 1\end{array}$ & $\begin{array}{l}1650 / 800 \\
1650 / 800 \\
1600 / 700 \\
1600 / 700\end{array}$ & $\begin{array}{l}20 \\
" 1 \\
"\end{array}$ & $\begin{array}{c}50 / 50 \\
50 / 50 \\
" 1\end{array}$ & $\begin{array}{c}48.4 / 122 \\
" 1 \\
78.8 / 123 \\
" 1\end{array}$ \\
\hline $\begin{array}{r}806 \\
810 \\
813 \\
814 \\
3018\end{array}$ & $\begin{array}{l}22 \\
23 \\
20 \\
21 \\
94\end{array}$ & $\begin{array}{ll}11 & D \\
11 & E \\
11 & B \\
11 & C \\
12 & C\end{array}$ & $\begin{array}{c}\mathrm{HfO}_{2} \\
" \\
" \\
"\end{array}$ & $\begin{array}{l}\lambda / 2 \\
11 \\
2 \lambda \\
" 1 \\
" 1\end{array}$ & $\begin{array}{l}D+S \\
D+S \\
D+S \\
D+S \\
D+S\end{array}$ & $\begin{array}{l}600 \\
" 1 \\
" 1 \\
"\end{array}$ & $\begin{array}{l}700 \\
650 \\
800 \\
700 \\
650\end{array}$ & $\begin{array}{r}100 \\
" 1 " \\
" 1 \\
20\end{array}$ & $\begin{array}{c}90 / 10 \\
1 " \\
" \\
85 / 15 .\end{array}$ & $\begin{array}{l}63.4 \\
62.3 \\
54.9 \\
65.2 \\
79.0\end{array}$ \\
\hline $\begin{array}{l}2519 \\
2591 \\
2592\end{array}$ & $\begin{array}{l}104 \\
105 \\
106\end{array}$ & $\begin{array}{l}13 \mathrm{D} \\
13 \mathrm{~F} \\
13 \mathrm{G}\end{array}$ & $\begin{array}{c}\mathrm{HfO}_{2} / \mathrm{SiO}_{2} \\
"\end{array}$ & $\begin{array}{c}\mathrm{SLL}\left(\mathrm{HL}_{11}\right)^{6} \mathrm{HLL} \\
"\end{array}$ & $\begin{array}{l}D+S \\
D+S \\
D+S\end{array}$ & $\begin{array}{c}600 / 600 \\
1 "\end{array}$ & $\begin{array}{l}850 / 550 \\
850 / 575 \\
875 / 550\end{array}$ & $\begin{array}{r}20 \\
" 1\end{array}$ & $\begin{array}{c}85 / 15 \\
" 1\end{array}$ & $\begin{array}{c}93.5 / 125.6 \\
" 1\end{array}$ \\
\hline $\begin{array}{l}3043 \\
3022 \\
3032\end{array}$ & $\begin{array}{l}93 \\
91 \\
92\end{array}$ & $\begin{array}{ll}11 & \mathrm{D} \\
11 & \mathrm{~B} \\
11 \mathrm{C}\end{array}$ & $\begin{array}{c}\mathrm{Y}_{211} \mathrm{O}_{3} \\
" 1\end{array}$ & $\begin{array}{l}\lambda / 2 \\
2 \lambda \\
11\end{array}$ & $\begin{array}{l}D+S \\
D+S \\
D+S\end{array}$ & $\begin{array}{l}600 \\
11\end{array}$ & $\begin{array}{l}900 \\
900 \\
900\end{array}$ & $\begin{array}{l}20 \\
20 \\
20\end{array}$ & $\begin{array}{c}85 / 15 \\
" 1\end{array}$ & $\begin{array}{l}97.4 \\
92.6 \\
92.9\end{array}$ \\
\hline $\begin{array}{l}2517 \\
2517 \\
2518 \\
2518 \\
2520\end{array}$ & $\begin{array}{r}99 \\
100 \\
101 \\
102 \\
103\end{array}$ & $\begin{array}{ll}12 & \mathrm{C} \\
12 & \mathrm{H} \\
12 & \mathrm{E} \\
12 & \mathrm{G} \\
12 & \mathrm{I}\end{array}$ & $\begin{array}{c}\mathrm{Y}_{2} \mathrm{O}_{3} / \mathrm{SiO}_{"} \\
" \\
" \\
"\end{array}$ & $\begin{array}{c}\mathrm{SLL}(\mathrm{HL})^{10} \\
" 1 \\
" \\
"\end{array}$ & $\begin{array}{l}D+S \\
D+S \\
D+S \\
D+S \\
D+S\end{array}$ & $\begin{array}{c}600 / 600 \\
" 1 \\
" 1 \\
"\end{array}$ & $\begin{array}{l}1000 / 700 \\
1050 / 600 \\
1100 / 675 \\
1050 / 625 \\
1050 / 650\end{array}$ & $\begin{array}{l}20 \\
" 1 \\
" 1\end{array}$ & $\begin{array}{c}85 / 15 \\
" 1 \\
" 1 \\
"\end{array}$ & $\begin{array}{c}90.4 / 127.7 \\
" \\
" \\
"\end{array}$ \\
\hline
\end{tabular}


TABLE 3: Damage Threshold of PNL Sputtered

Coatings At $248 \mathrm{~nm}, 20 \mathrm{~ns}$

\begin{tabular}{|c|c|c|c|c|c|c|c|c|c|c|c|c|c|}
\hline $\begin{array}{l}\text { LLNL } \\
\text { Substrate\# }\end{array}$ & $\begin{array}{l}\text { Damage } \\
\text { Test\# }\end{array}$ & $\begin{array}{l}\text { PNL } \\
\text { Coating\# }\end{array}$ & $\begin{array}{l}\text { Coating } \\
\text { Material }\end{array}$ & $\begin{array}{l}\text { Coating } \\
\text { Design }\end{array}$ & ${ }_{\%}^{0_{2}}$ & $\begin{array}{l}\lambda \\
\mathrm{nm}\end{array}$ & $\begin{array}{l}R \\
\%\end{array}$ & $\begin{array}{l}\text { Sub- } \\
\text { strate }\end{array}$ & $\begin{array}{l}\text { Substrate } \\
\text { Polish/Prep. }\end{array}$ & $\begin{array}{l}\text { Beam } \\
\text { Polar. }\end{array}$ & Comments & $\begin{array}{r}\text { Clean } \\
0-3\end{array}$ & $\begin{array}{l}\text { Threstrold } \\
\mathrm{J} / \mathrm{cm}^{\mathrm{C}}\end{array}$ \\
\hline $\begin{array}{l}804 \\
805 \\
811 \\
812 \\
808 \\
803 \\
807 \\
809\end{array}$ & $\begin{array}{l}14 \\
15 \\
18 \\
19 \\
12 \\
13 \\
16 \\
17\end{array}$ & $\begin{array}{ll}11 & D \\
11 & E \\
12 & D \\
12 & E \\
11 & B \\
11 & C \\
12 & B \\
12 & C\end{array}$ & $\begin{array}{c}\mathrm{Al}_{2}{ }^{0} 3 \\
" \\
" \\
" \\
" \\
" \\
"\end{array}$ & $\begin{array}{c}\lambda / 2 \\
" \\
" \\
3 \lambda / 2 \\
" 1 " \\
2 \lambda \\
" 1\end{array}$ & $\begin{array}{l}15 \\
15 \\
50 \\
50 \\
15 \\
15 \\
50 \\
50\end{array}$ & & & $\begin{array}{l}\text { FS } \\
" 1 \\
" 1 \\
" 1 \\
" 1 \\
" 1\end{array}$ & $\begin{array}{l}\text { Rear, D+S } \\
\text { D } \\
\text { D } \\
D+S \\
\text { D } \\
\text { D+S } \\
\text { D } \\
D+S\end{array}$ & $\begin{array}{l}\mathrm{s} \\
\mathrm{s} \\
\mathrm{S} \\
\mathrm{s} \\
\mathrm{s} \\
\mathrm{s} \\
\mathrm{s} \\
\mathrm{s}\end{array}$ & $\begin{array}{l}\text { Large flaws } \\
\text { Voids, droplets } \\
\text { Thresh. cracks }\end{array}$ & $\begin{array}{l}1 \\
1 \\
1 \\
0 \\
2 \\
2 \\
2 \\
1\end{array}$ & $\begin{array}{l}1.6 \pm 0.2 \\
1.7 \pm 0.2 \\
2.6 \pm c .4 \\
3.2 \pm 0.3 \\
1.7 \pm 0.2 \\
2.1 \pm 0.2 \\
1.9 \pm 0.2 \\
1.5 \pm 0.2\end{array}$ \\
\hline $\begin{array}{l}2504 \\
2505 \\
2514 \\
2515\end{array}$ & $\begin{array}{l}95 \\
96 \\
97 \\
98\end{array}$ & $\begin{array}{ll}14 & C \\
14 & D \\
14 & H \\
14 & I\end{array}$ & $\begin{array}{c}\mathrm{Al}_{2} \mathrm{O}_{3} / \mathrm{SiO}_{n} \\
" 1 " \\
"\end{array}$ & $\begin{array}{c}\operatorname{SLL}\left(\mathrm{HL}_{1}\right)^{19} \mathrm{HLL} \\
" \\
"\end{array}$ & & $\begin{array}{l}248 \\
255 \\
249 \\
257\end{array}$ & $\begin{array}{l}81 \\
83 \\
83 \\
80\end{array}$ & $\begin{array}{l}\text { BK-7 } \\
" 1 \\
" 1\end{array}$ & $\begin{array}{l}D+S \\
D+S \\
\text { Rear, D+S } \\
\text { Rear, D+S }\end{array}$ & $\begin{array}{l}\mathbf{p} \\
\mathbf{p} \\
\mathbf{p} \\
\mathbf{p}\end{array}$ & Scuffs, green thresh. & $\begin{array}{r}2 \\
2 \\
2 \\
2\end{array}$ & $\begin{array}{l}2.3 \pm 0.2 \\
2.0 \pm 0.2 \\
2.3 \mp 0.2 \\
2.3 \pm 0.2\end{array}$ \\
\hline $\begin{array}{r}806 \\
810 \\
813 \\
814 \\
3018\end{array}$ & $\begin{array}{l}22 \\
23 \\
20 \\
21 \\
94\end{array}$ & $\begin{array}{ll}11 & \mathrm{D} \\
11 & \mathrm{E} \\
11 & \mathrm{~B} \\
11 & \mathrm{C} \\
12 & \mathrm{C}\end{array}$ & $\begin{array}{c}\mathrm{HfO}_{2} \\
" 1 \\
" \\
"\end{array}$ & $\begin{array}{l}\lambda / 2 \\
" 1 \\
2 \lambda \\
" 1\end{array}$ & & & & $\begin{array}{l}\text { FS } \\
" 1 \\
" 1 \\
" 1\end{array}$ & $\begin{array}{l}D+S \\
D+S \\
D+S \\
D+S \\
\text { Super, D+S }\end{array}$ & $\begin{array}{l}\text { s } \\
\text { s } \\
\text { s } \\
\text { s } \\
\text { p }\end{array}$ & $\begin{array}{l}\text { Yellow edge } \\
\text { Colored edge, fog } \\
\text { Splotched, fog } \\
\text { Splotched, very foggy }\end{array}$ & $\begin{array}{r}2 \\
2 \\
3 \\
3 \\
\times 3\end{array}$ & $\begin{array}{l}0.5 \pm 0.1 \\
0.5 \mp 0.1 \\
0.8 \mp 0.2 \\
0.7 \mp 0.1 \\
0.3 \pm 0.1\end{array}$ \\
\hline $\begin{array}{l}2519 \\
2591 \\
2592\end{array}$ & $\begin{array}{l}104 \\
105 \\
106\end{array}$ & $\begin{array}{ll}13 & \mathrm{D} \\
13 \mathrm{~F} \\
13 \mathrm{G}\end{array}$ & $\underset{1 "}{\mathrm{HfO}_{2} / \mathrm{SiO}_{2}}$ & $\begin{array}{c}\mathrm{SLL}\left(\mathrm{HL}_{1}\right)^{6} \mathrm{HLL} \\
"\end{array}$ & & $\begin{array}{l}249 \\
266 \\
253\end{array}$ & $\begin{array}{l}96 \\
96 \\
94\end{array}$ & $\begin{array}{l}\text { BK-7 } \\
" 1\end{array}$ & $\begin{array}{l}D+S \\
D+S \\
D\end{array}$ & $\begin{array}{l}p \\
p \\
p\end{array}$ & $\begin{array}{l}\text { Vague Threshold } \\
\text { Vague Threshold }\end{array}$ & $\begin{array}{l}3 \\
2 \\
2\end{array}$ & $\begin{array}{l}2.1 \pm 0.2 \\
0.9 \pm 0.1 \\
1.0 \pm 0.4\end{array}$ \\
\hline $\begin{array}{l}3043 \\
3022 \\
3032\end{array}$ & $\begin{array}{l}93 \\
91 \\
92\end{array}$ & $\begin{array}{ll}11 & \mathrm{D} \\
11 & \mathrm{~B} \\
11 & \mathrm{C}\end{array}$ & $\begin{array}{c}\mathrm{r}_{20} \mathrm{O}_{3} \\
"\end{array}$ & $\begin{array}{l}\lambda / 2 \\
2 \lambda \\
" 1\end{array}$ & & & & $\begin{array}{l}\text { FS } \\
" 1\end{array}$ & $\begin{array}{l}\text { Super, D+S } \\
\text { Super, D+S } \\
\text { Super, } D+S\end{array}$ & $\begin{array}{l}p \\
p \\
p\end{array}$ & Artifacts damage & $\begin{array}{l}1 \\
3 \\
3\end{array}$ & $\begin{array}{l}1.1+0.1 \\
0.6 \pm 0.1 \\
<0.3\end{array}$ \\
\hline $\begin{array}{l}2517 \\
11 \\
2518 \\
11 \\
2520\end{array}$ & $\begin{array}{r}99 \\
100 \\
101 \\
102 \\
103\end{array}$ & $\begin{array}{ll}12 & \mathrm{C} \\
12 & \mathrm{H} \\
12 & \mathrm{E} \\
12 & \mathrm{G} \\
12 & \mathrm{I}\end{array}$ & $\begin{array}{c}\mathrm{r}_{2} \mathrm{O}_{3} / \mathrm{SiO}_{1} \\
" \\
" \\
"\end{array}$ & $\begin{array}{c}\operatorname{SLL}(H L)^{10} \\
" 1 \\
" \\
"\end{array}$ & & $\begin{array}{l}258 \\
244 \\
280 \\
247 \\
252\end{array}$ & $\begin{array}{l}67 \\
62 \\
80 \\
67 \\
73\end{array}$ & $\begin{array}{l}\text { BK-7 } \\
11 \\
" 1 \\
" 1 \\
"\end{array}$ & $\begin{array}{l}\text { D+S } \\
\text { Rear, D+S } \\
\text { D+S } \\
\text { Rear, D+S } \\
D+S\end{array}$ & $\begin{array}{l}p \\
p \\
p \\
p \\
p\end{array}$ & $\begin{array}{l}\text { Droplets } \\
\text { Smudges } \\
\text { Scuffs }\end{array}$ & $\begin{array}{l}2 \\
2 \\
2 \\
1 \\
0\end{array}$ & $\begin{array}{l}0.4+0.2 \\
0.6 \mp 0.2 \\
0.5 \div 0.1 \\
0.6 \mp 5.3 \\
0.7 \pm 0.1\end{array}$ \\
\hline
\end{tabular}


TABLE 4: Absorption And Extinction Coefficients At $248 \mathrm{~nm}$ For Each Coating Material Deduced From Figures 12 through 15 . The Values For $\mathrm{HfO}_{2}, \mathrm{Y}_{2} \mathrm{O}_{3}$, and $\mathrm{A}_{2} \mathrm{O}_{3}$ Are Upper Limits As Explained In The Text.

Coating

Material

$\mathrm{SiO}_{2}$

$\mathrm{Al}_{2} \mathrm{O}_{3}$

$\mathrm{Y}_{2} \mathrm{O}_{3}$

$\mathrm{HfO}_{2}$

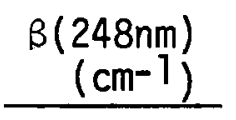

210

2600

1770

3900
.0035

$k(248 n m)$

.00041

.0051

.0077 
TABLE 5: Fit Parameters For Least Squares Analys is of Refractive Index Dispersion According To The Relation $\mathrm{n}^{2}=1+\frac{A}{1-\mathrm{B} / \lambda^{2}}$

\begin{tabular}{lccccc} 
Material & \multicolumn{1}{c}{$\mathrm{A}$} & $\mathrm{B}$ & & $(1+\mathrm{A})^{1 / 2}$ & $\mathrm{n}(248 \mathrm{~nm})$ \\
$\mathrm{SiO}_{2}$ & 1.0931 & 6599 & 1.447 & 1.491 \\
$\mathrm{Al}_{2} \mathrm{O}_{3}$ & 1.7035 & 8236 & 1.644 & 1.722 \\
$\mathrm{Y}_{2} \mathrm{O}_{3}$ & 2.4261 & 20912 & 1.851 & 2.162 \\
$\mathrm{HfO}_{2}$ & 2.8557 & 23545 & 1.964 & 2.372
\end{tabular}


TABLE 6: Microstructural Properties Deduced From

$X$-Ray Diffractometer Data For Single Layers.

\begin{tabular}{llll} 
Material & $\begin{array}{c}\text { Crystal } \\
\text { Structure }\end{array}$ & $\begin{array}{c}\text { Grain } \\
\text { Size }(\AA)\end{array}$ & $\begin{array}{c}\text { Preferred } \\
\text { Orientation }\end{array}$ \\
\cline { 2 - 2 } & Glassy & Glassy & $-\cdots$ \\
$\mathrm{Al}_{2} \mathrm{O}_{3}$ & Cubic $(\dot{\gamma})$ & $30-100$ & Random \\
$\mathrm{Y}_{2} \mathrm{O}_{3}$ & Cubic & $340-540$ & $\begin{array}{l}(222) \\
\text { v. str. }(.90)\end{array}$ \\
$\mathrm{HfO}_{2}$ & Monoclinic & $100-300$ & $(11 \overline{1})$ \\
& & & str. $(.65)$
\end{tabular}


TABLE 7: Transmission And Absorption/Scattering Losses For High Reflectors With Tuned Wavelengths Near $248 \mathrm{~nm}$ Made From Three Coating Material Combinations.

\begin{tabular}{|c|c|c|c|c|c|c|}
\hline $\begin{array}{c}\text { Coating } \\
\text { Materials }\end{array}$ & $\begin{array}{c}\text { PNL } \\
\text { Coating\# }\end{array}$ & $\begin{array}{r}\lambda_{0} \\
(\mathrm{~nm}) \\
\end{array}$ & $\begin{array}{c}R\left(\lambda_{0}\right) \\
(\%) \\
\end{array}$ & $\begin{array}{c}T\left(\lambda_{0}\right) \\
(\%)\end{array}$ & $\begin{array}{c}A+S(\lambda 0) \\
(\%) \\
\end{array}$ & $\begin{array}{c}A\left(\lambda_{0}\right)^{\star} \\
(\%)\end{array}$ \\
\hline \multirow[t]{3}{*}{$\mathrm{HfO}_{2} / \mathrm{SiO}_{2}$} & $13 E-4$ & 225 & 95.4 & 1.0 & 3.6 & 1.5 \\
\hline & $13 E-1$ & 225 & 99.0 & 0.9 & 0.1 & 1.5 \\
\hline & $13 \mathrm{~J}$ & 228 & 99.2 & 0.6 & 0.2 & 1.5 \\
\hline \multirow[t]{6}{*}{$\mathrm{Y}_{2} \mathrm{O}_{3} / \mathrm{SiO}_{2}$} & $11 M$ & 237 & 55.0 & 12.8 & .32 .2 & 1.0 \\
\hline & $12 B-1$ & 258 & 64.7 & 5.9 & 29.4 & 1.0 \\
\hline & $11 \mathrm{~L}$ & 259 & 81.8 & 4.6 & 13.6 & 1.0 \\
\hline & $12 B-2$ & 263 & 78.2 & 4.6 & 17.2 & 1.0 \\
\hline & $11 \mathrm{~J}$ & 269 & 83.3 & 1.5 & 15.2 & 1.0 \\
\hline & $11 \mathrm{~K}$ & 270 & 81.7 & 5.5 & 12.8 & 1.0 \\
\hline \multirow[t]{3}{*}{$\mathrm{Al}_{2} \mathrm{O}_{3} / \mathrm{SiO}_{2}$} & $13 \mathrm{~B}-1$ & 227 & 87.6 & 8.2 & 4.2 & 4.7 \\
\hline & $14 B$ & 228 & 86.0 & 6.6 & 7.4 & 4.7 \\
\hline & $13 \mathrm{~B}-2$ & 230 & 86.1 & 3.7 & 10.2 & 4.7 \\
\hline
\end{tabular}

* Calculated maximum value 


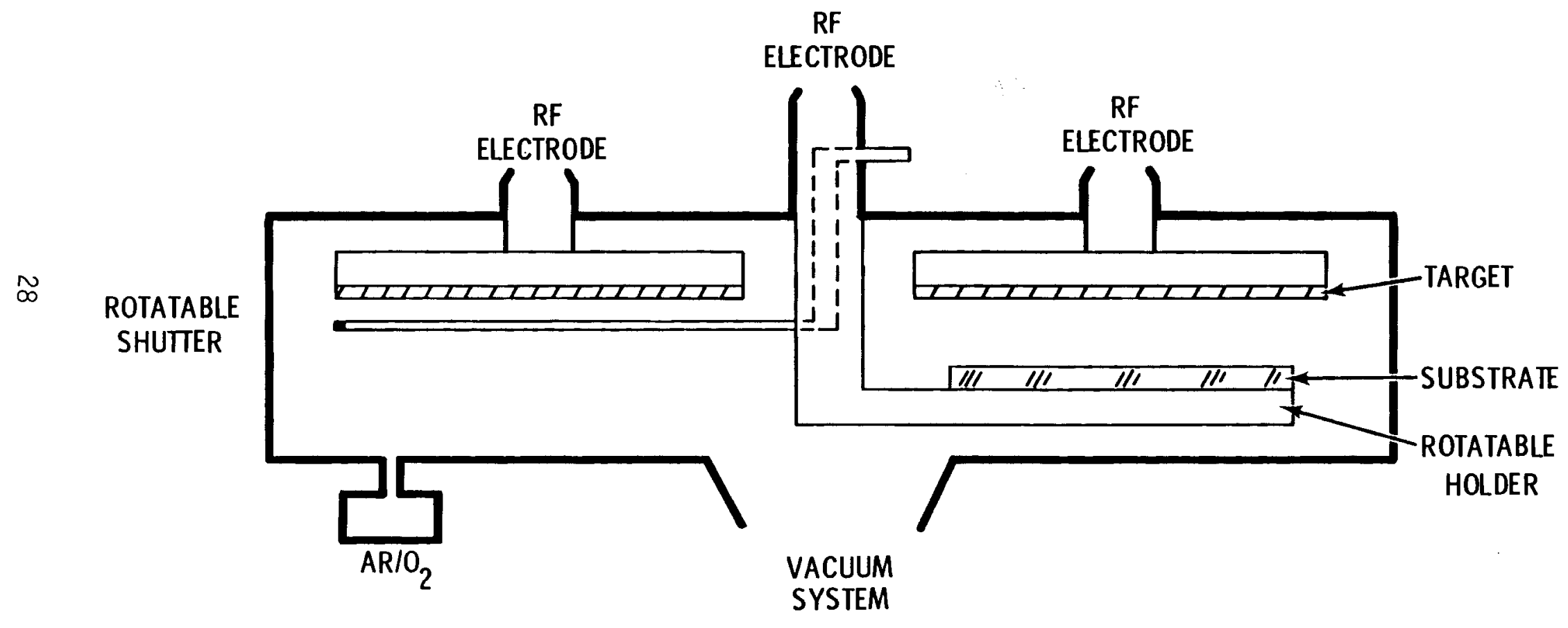

Figure 1. Schematic diagram of rf diode sputtering system used for coating deposition. 


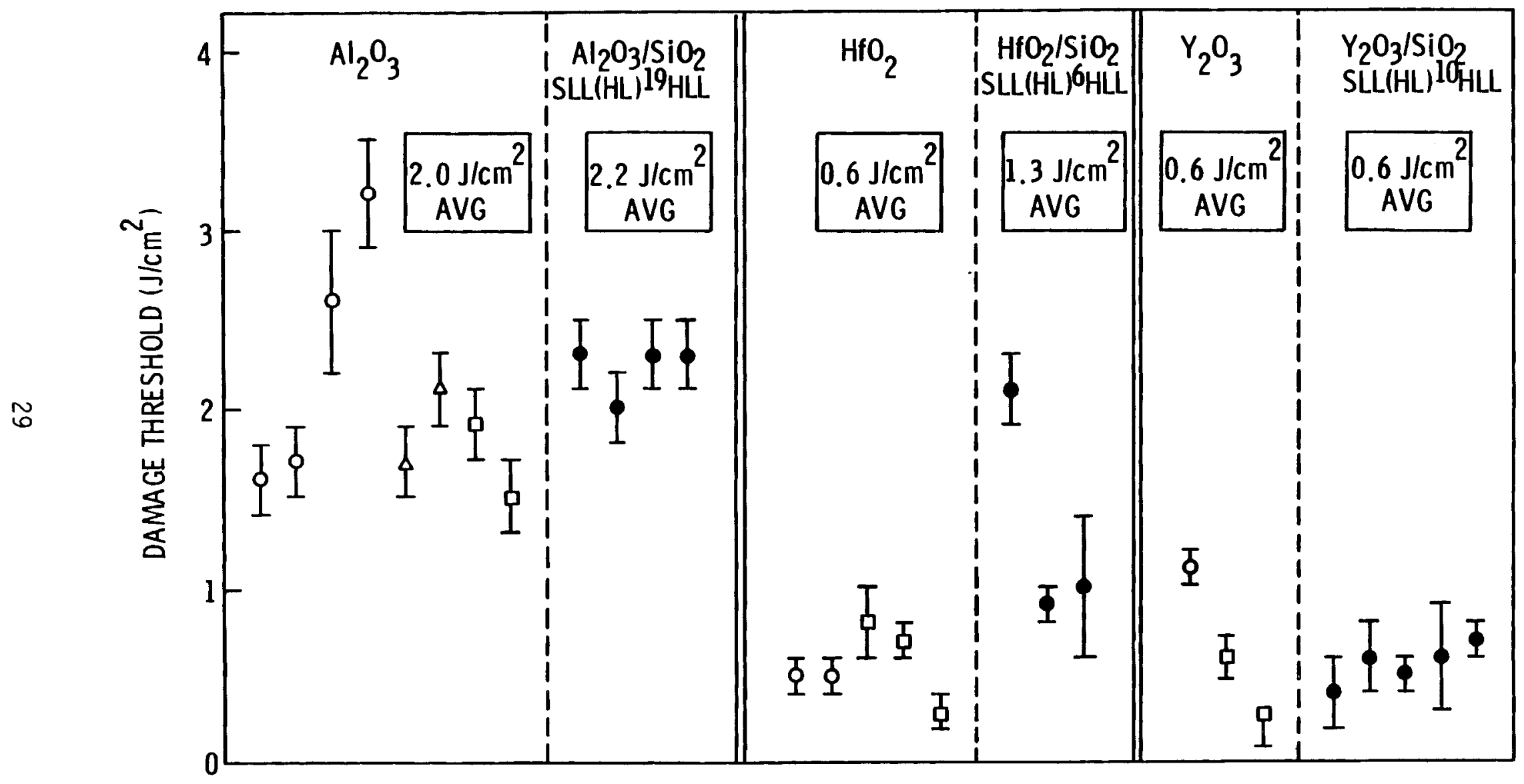

- SINGLE LAYER $\lambda / 2$

$\triangle$ SINGLE LAYER 3N2

口 SINGLE LAYER 4N2

- MULTIPLE LAYER REFLECTOR

Figure 2. Damage thresholds of PNL sputtered coatings at $248 \mathrm{~nm}, 20 \mathrm{~ns}$. 


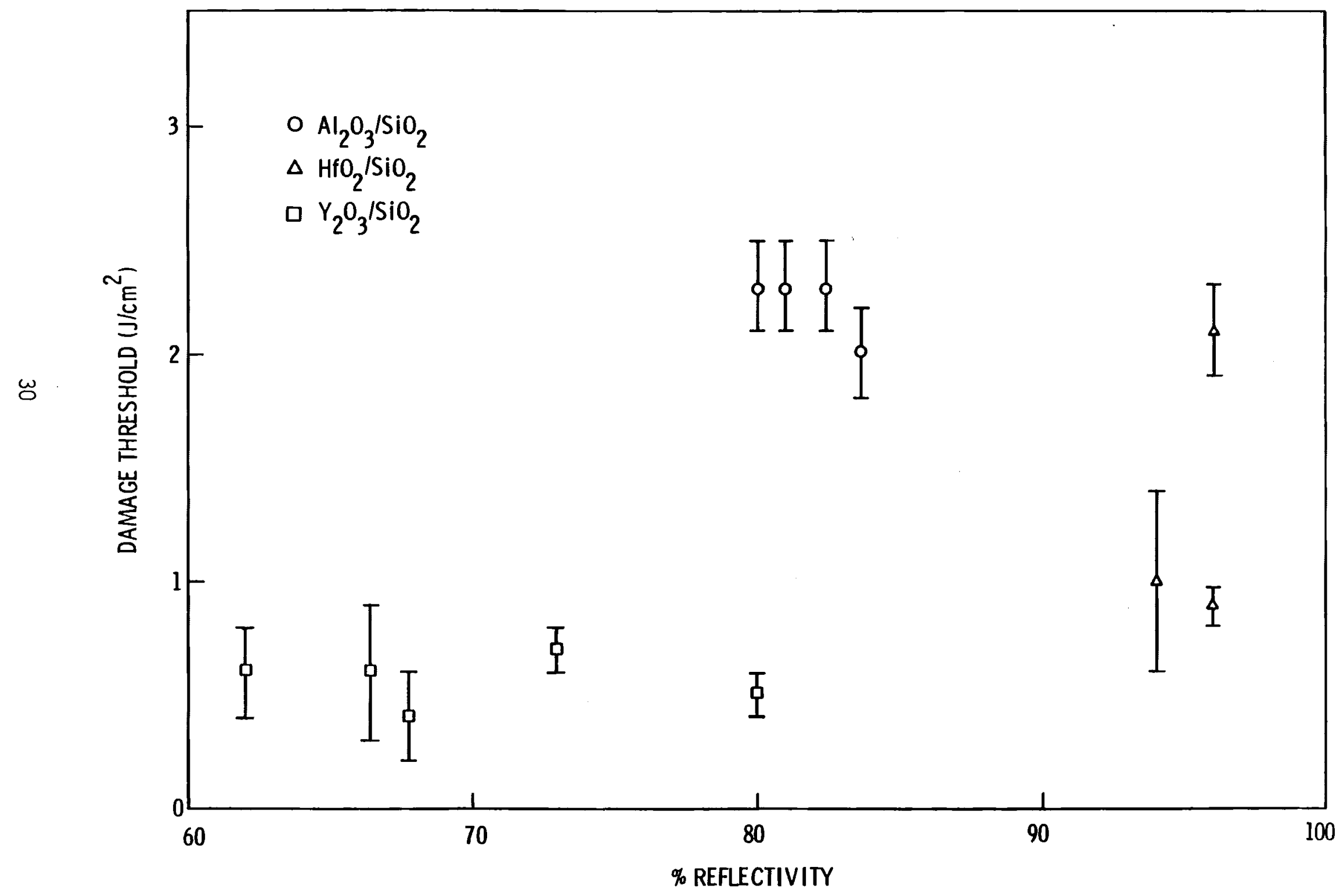

Figure 3. Lack of correlation between damage threshold and mirror reflectivity. 


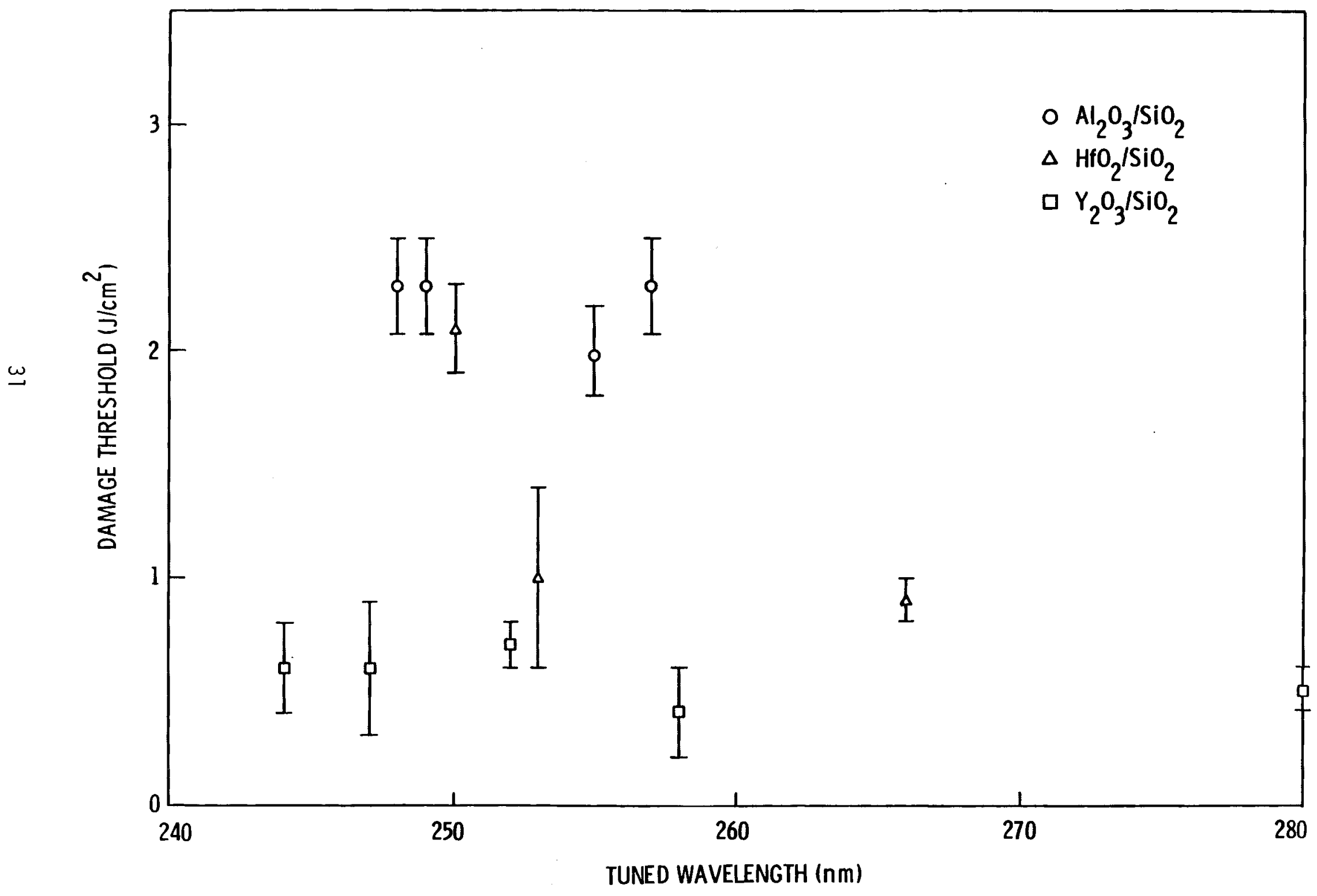

Figure 4. Lack of correlation between damage threshold and mirror tuned wavelength. 


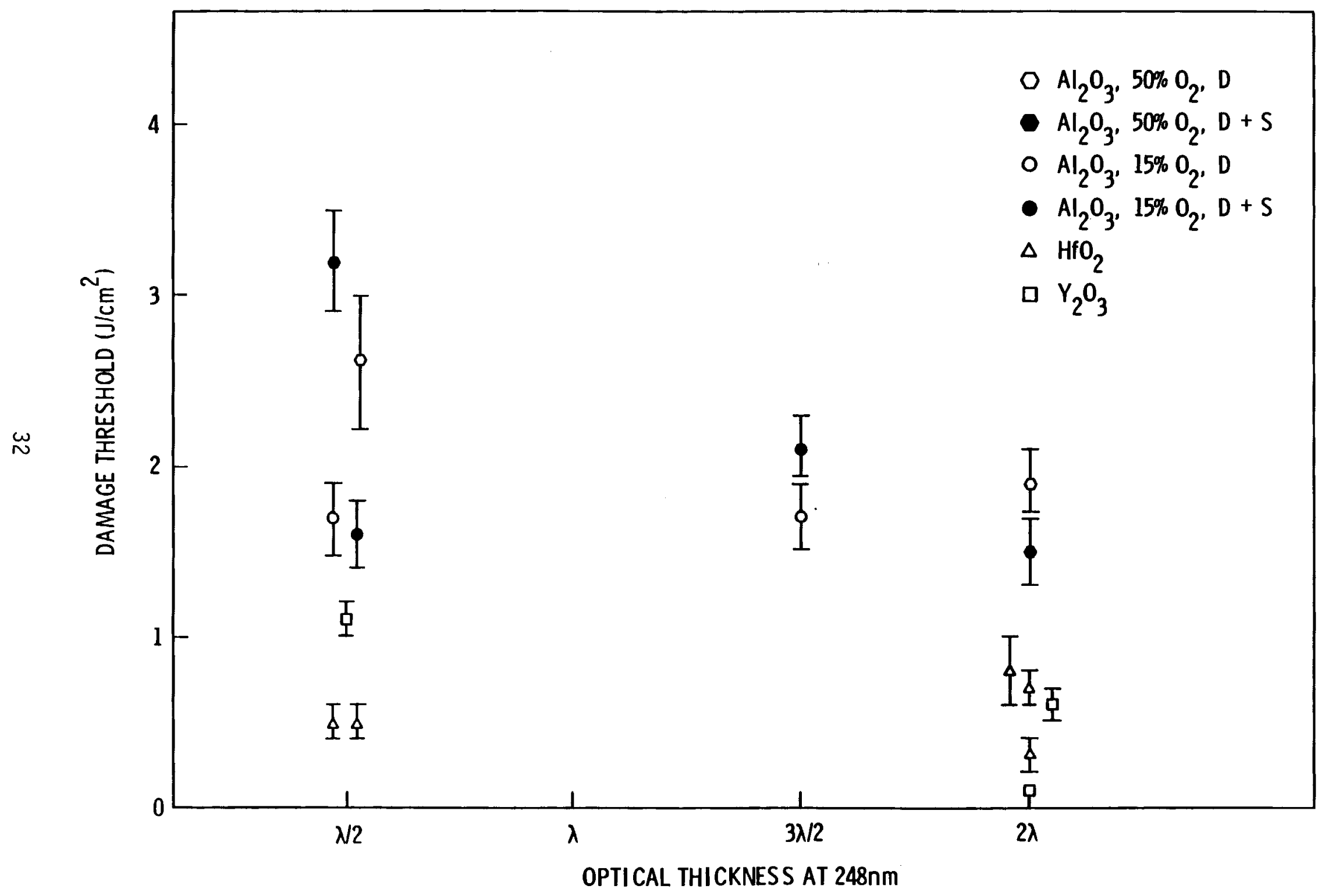

Figure 5. Lack of correlation between damage threshold and single-layer coating thickness, $0_{2}$ partial pressure or substrate cleaning procedure. 


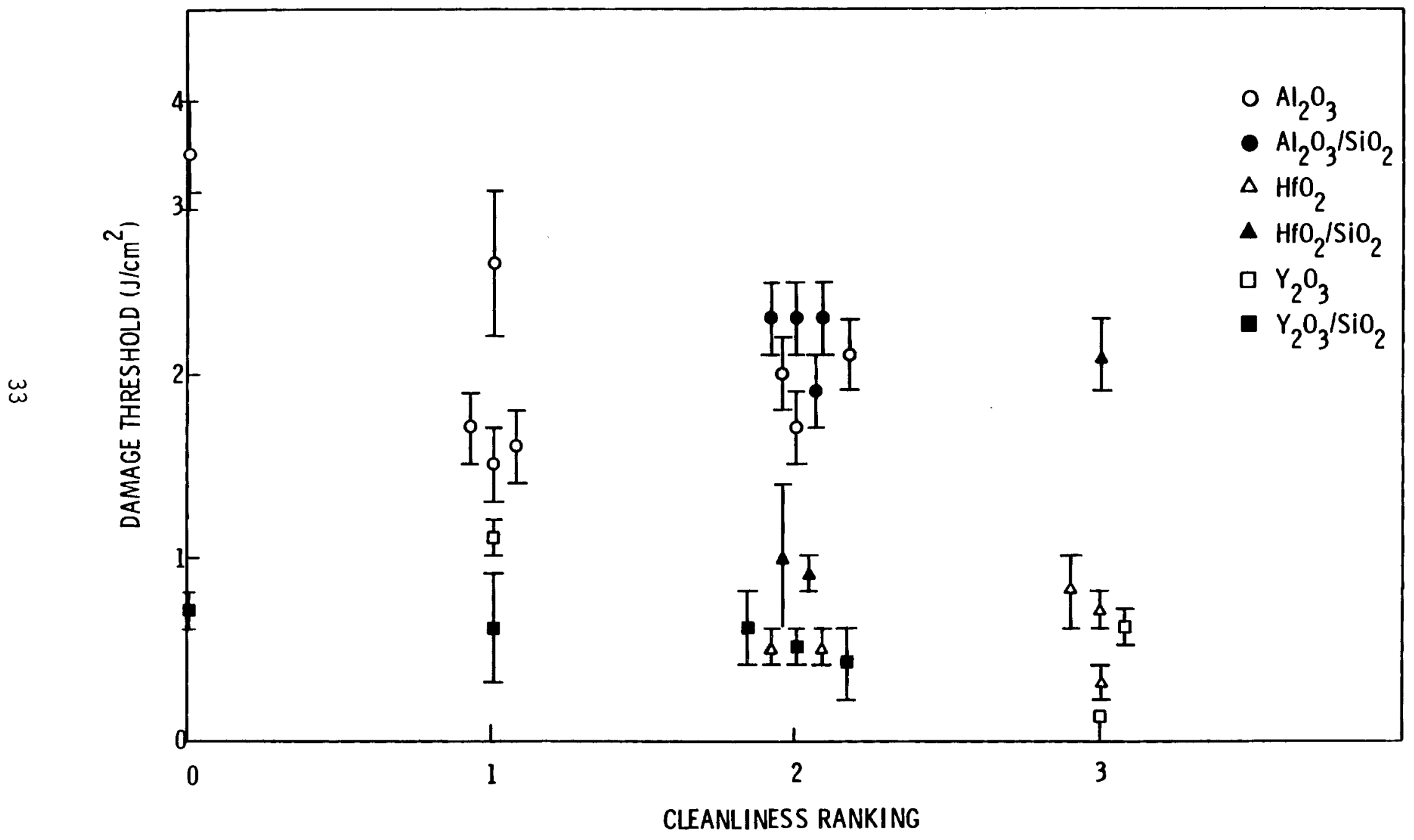

Figure 6. Intragroup correlation between damage threshold and coating "cleanliness" ranking. 


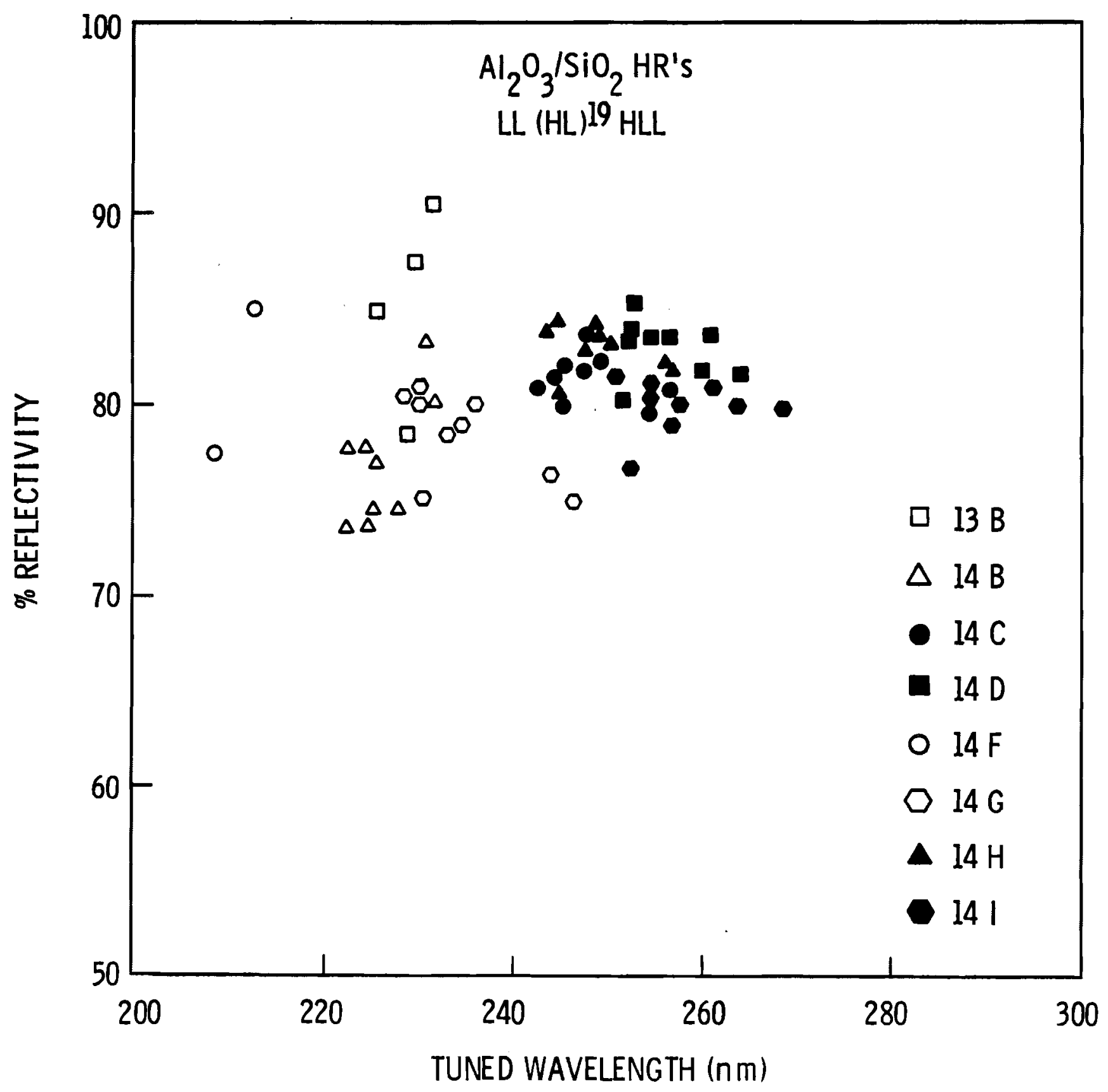

Figure 7. Variation of reflectivity of $\mathrm{Al}_{2} \mathrm{O}_{3} / \mathrm{SiO}_{2}$ mirrors with tuned wavelength. 


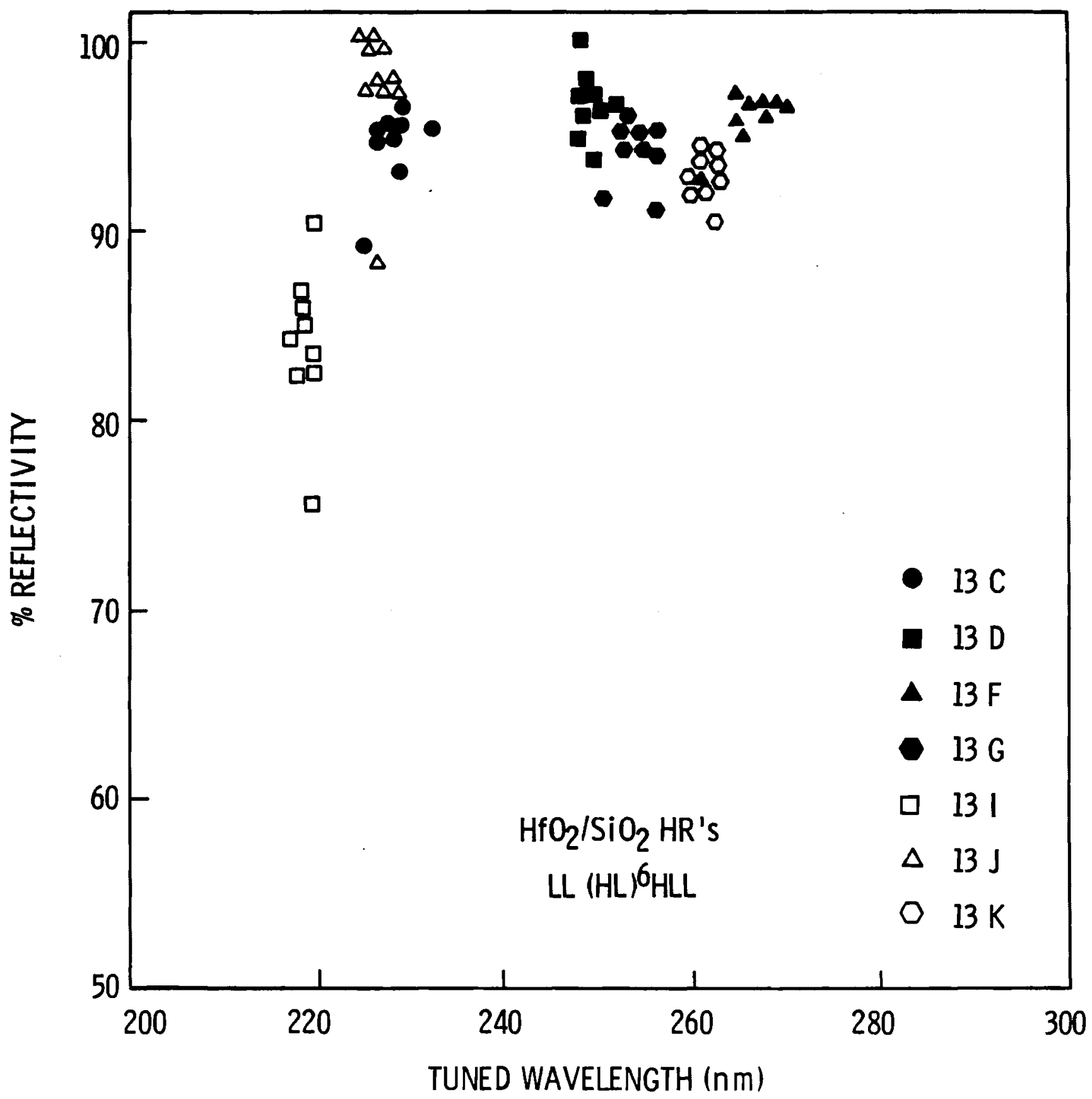

Figure 8. Variation of reflectivity of $\mathrm{HfO}_{2} / \mathrm{SiO}_{2}$ mirrors with tuned wavelength. 


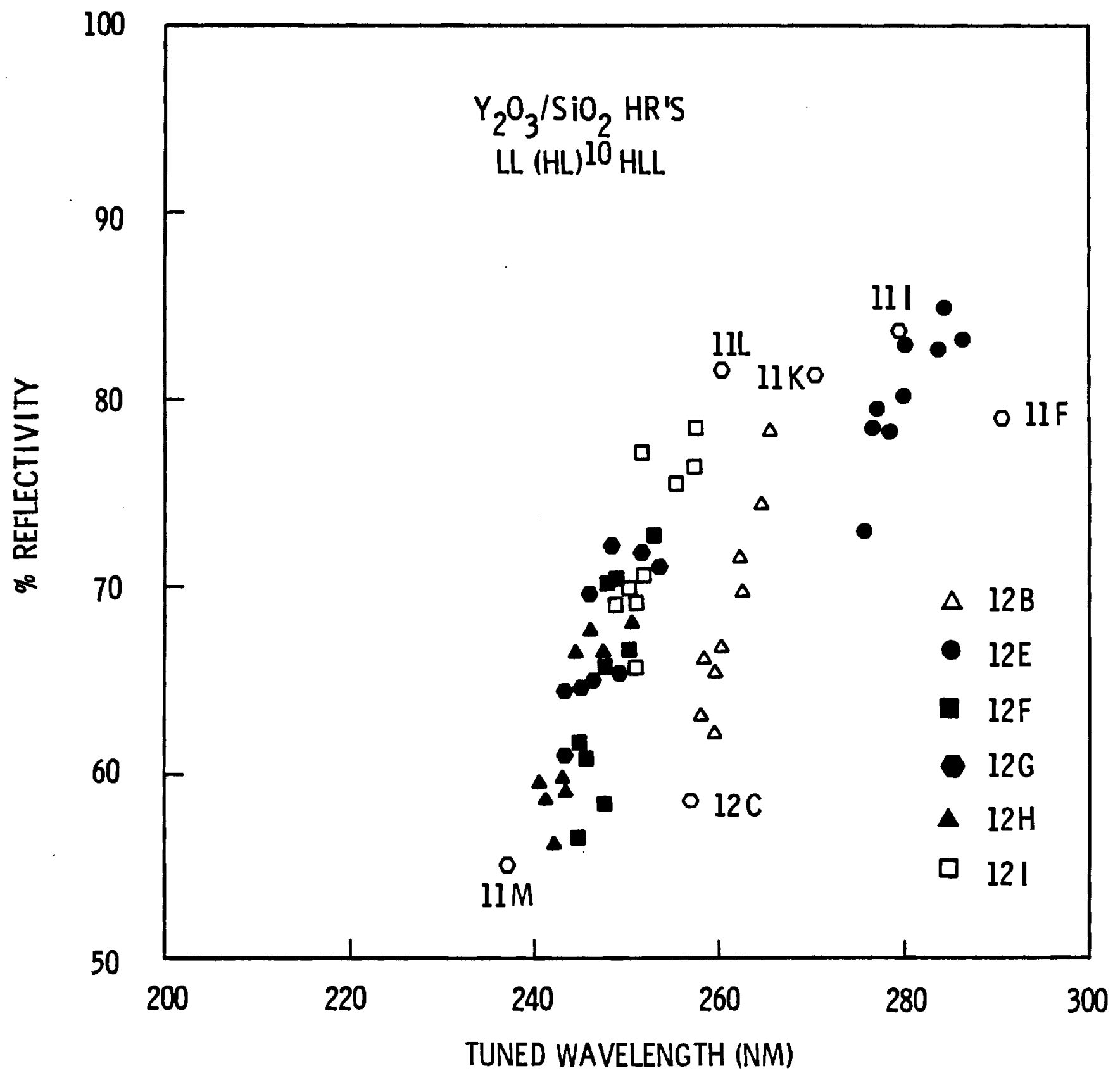

Figure 9. Variation of reflectivity of $\mathrm{Y}_{2} \mathrm{O}_{3} / \mathrm{SiO}_{2}$ mirrors with tuned wavelength. 


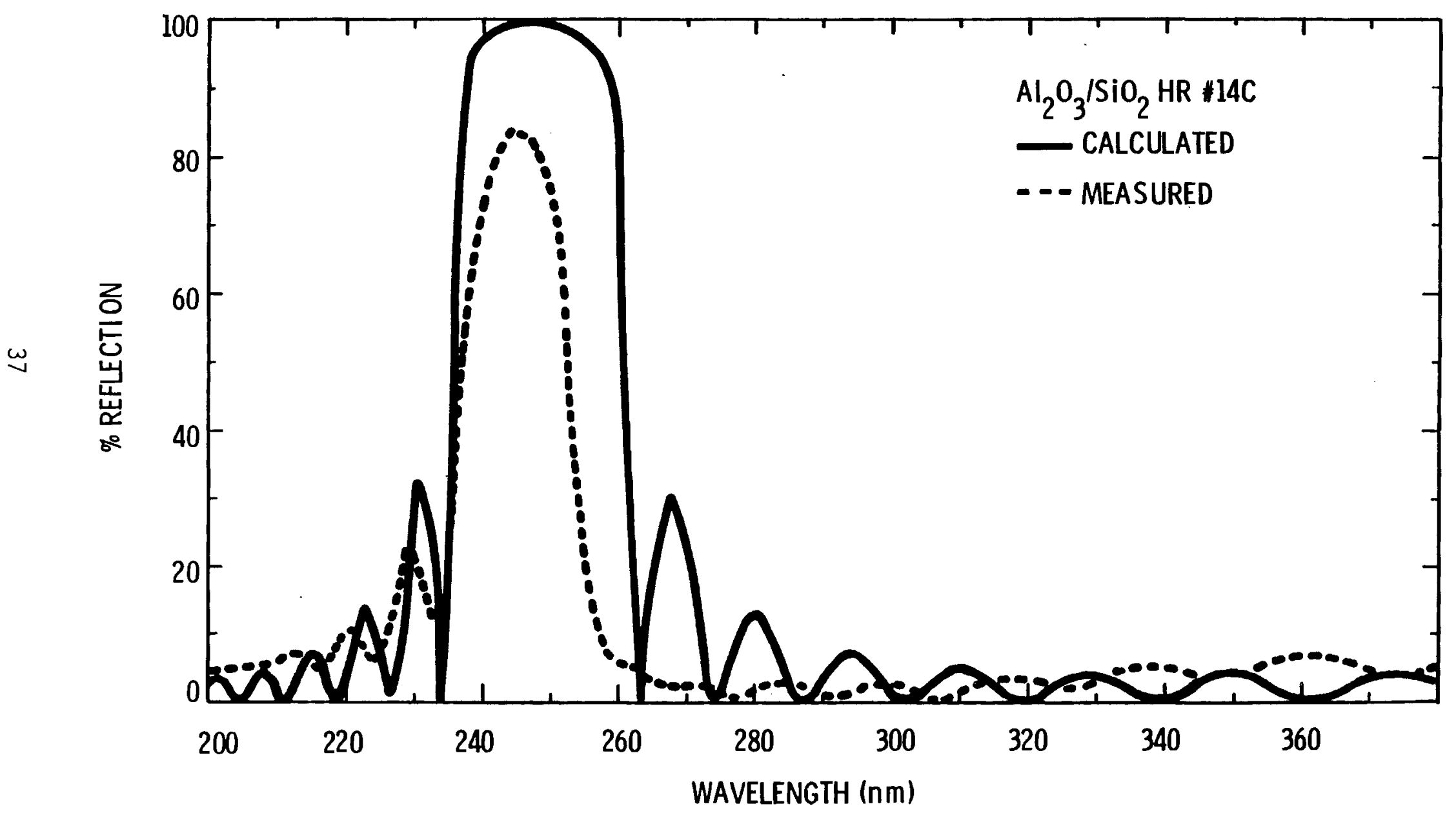

Figure 10. Spectral dependence of the reflectivity for an $\mathrm{Al}_{2} \mathrm{O}_{3} / \mathrm{SiO}_{2}$ high reflector. 


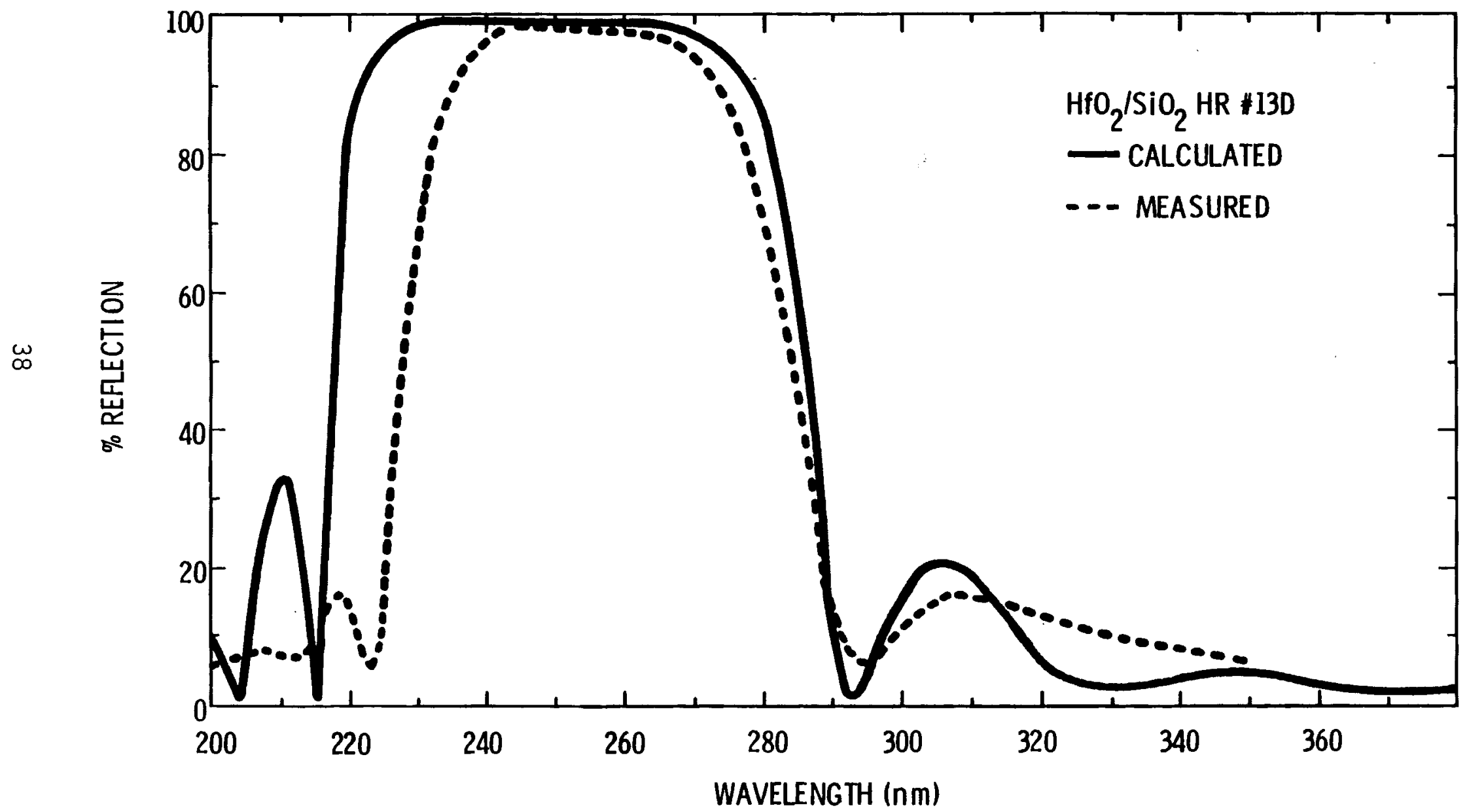

Figure 11. Spectral dependence of the reflectivity for a $\mathrm{HfO}_{2} / \mathrm{SiO}_{2}$ high reflector. 


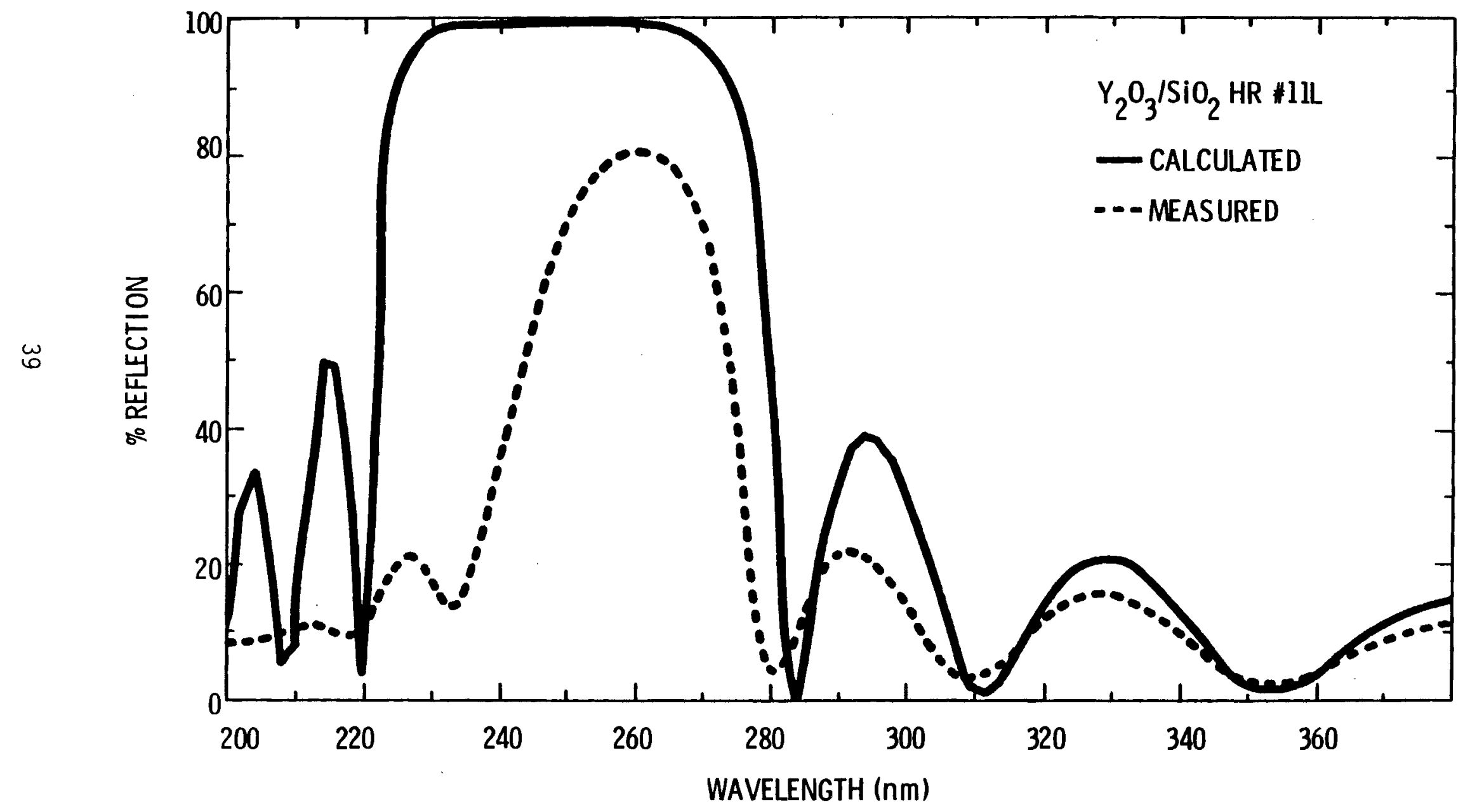

Figure 12. Spectral dependence of the reflectivity for an $\mathrm{Y}_{2} \mathrm{O}_{3} / \mathrm{SiO}_{2}$ high reflector. 


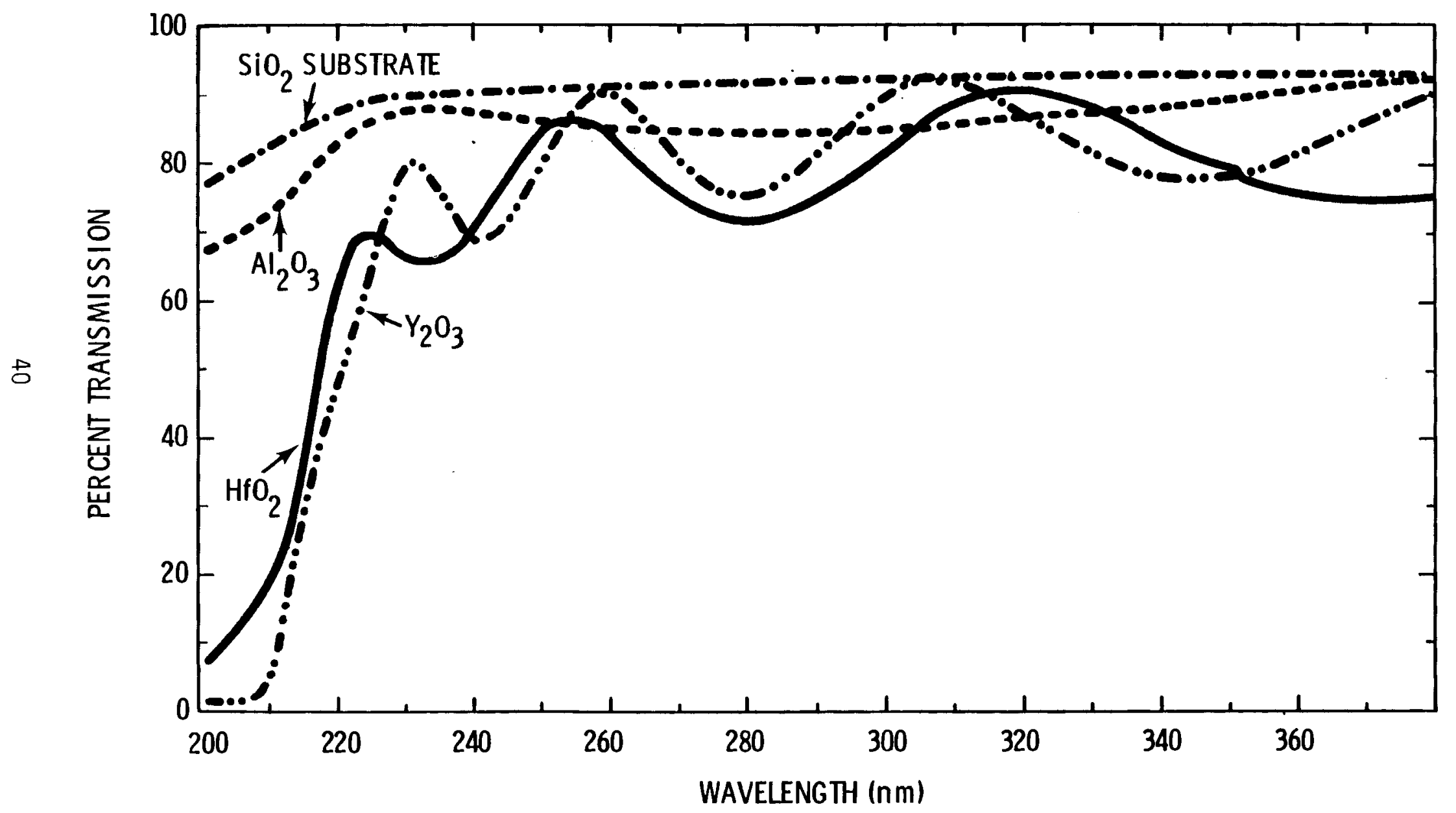

Figure 13. Transmission spectra for single layers of $\mathrm{HfO}_{2}, \mathrm{Y}_{2} \mathrm{O}_{3}$ and $\mathrm{Al}_{2} \mathrm{O}_{3}$ on fused
silica substrates. 


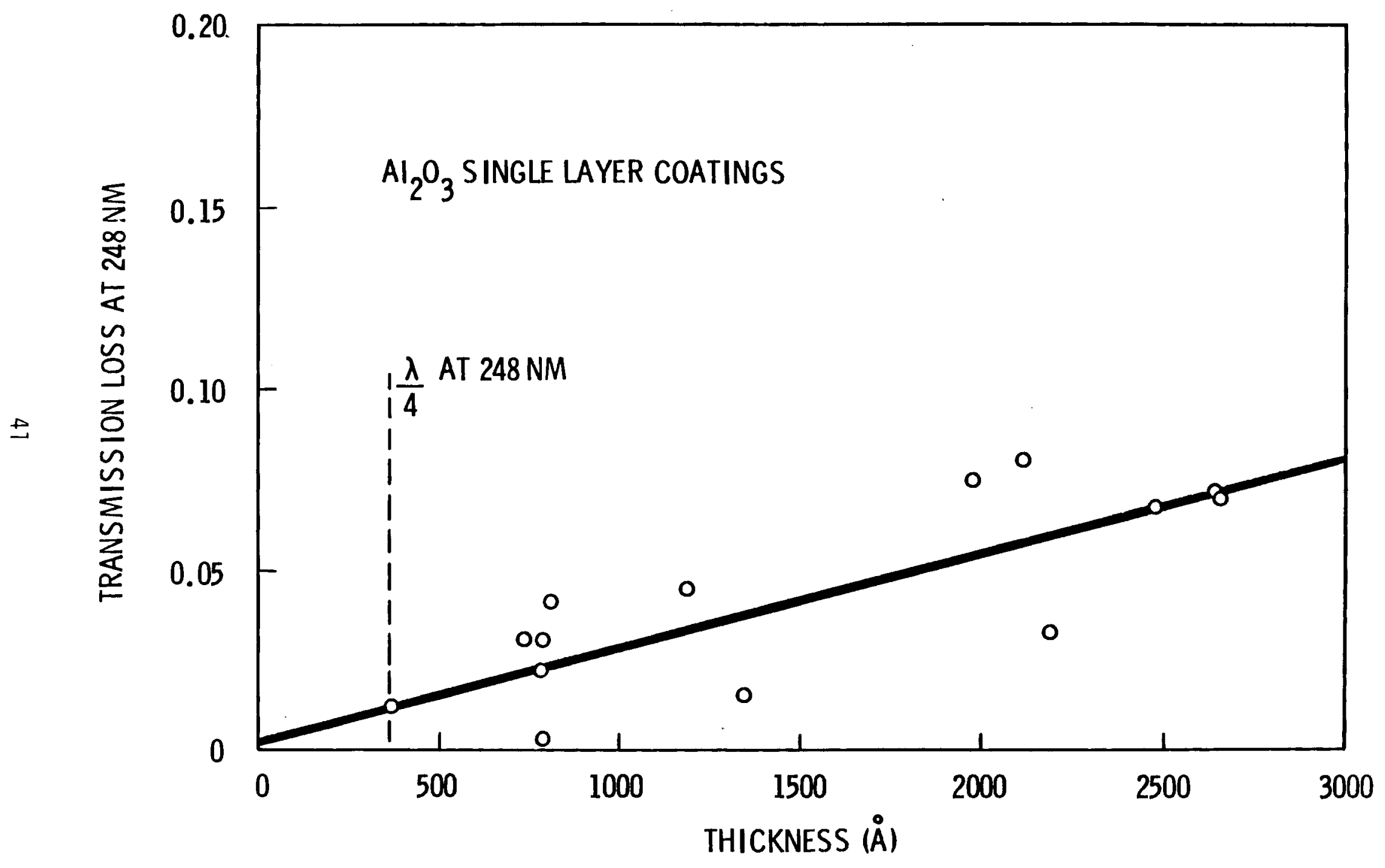

Figure 14. Dependence of $\mathrm{Al}_{2} \mathrm{O}_{3}$ scattering/absorption loss at $248 \mathrm{~nm}$ on single-layer coating thickness. 


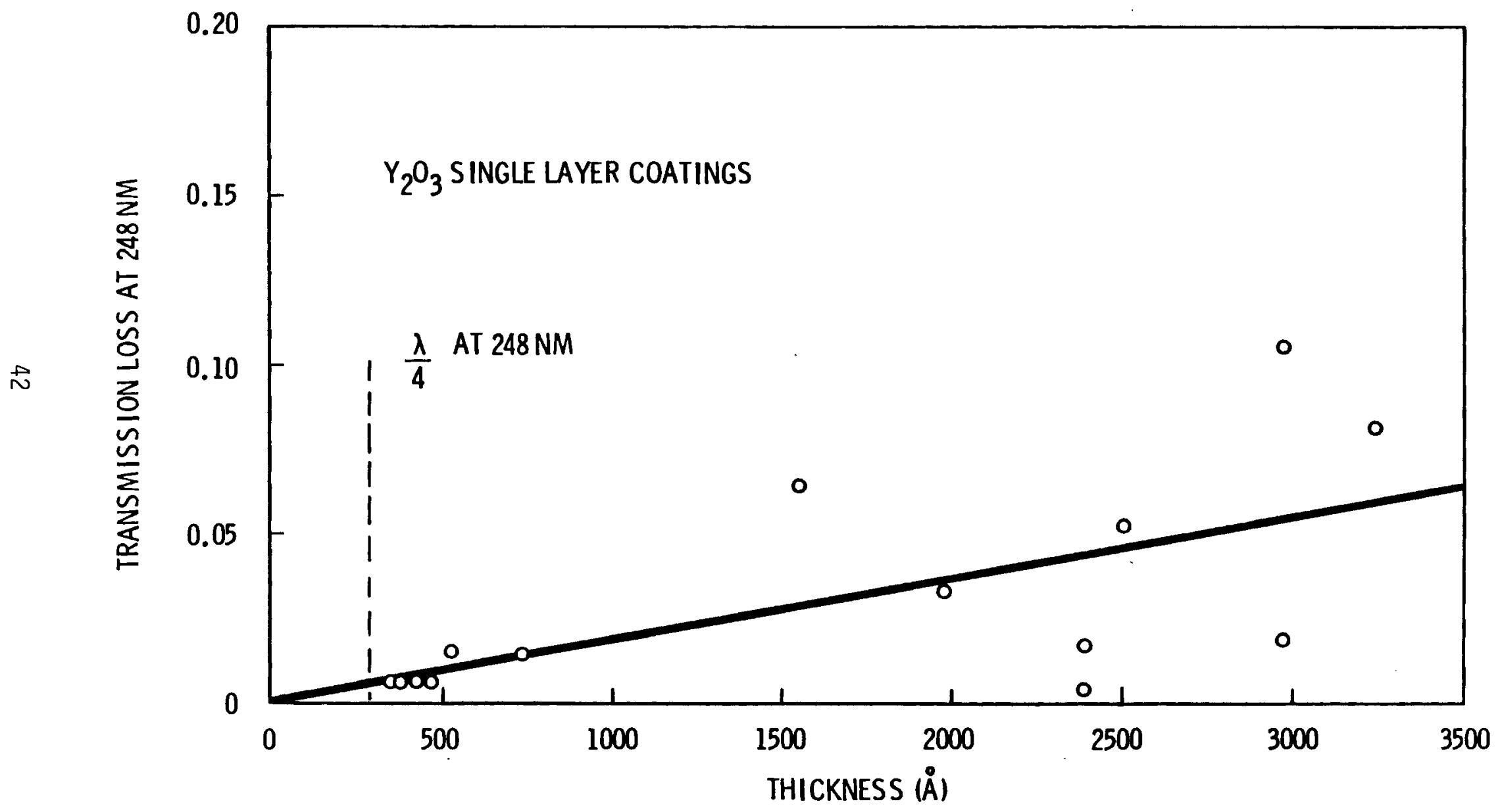

Figure 15. Dependence of $\mathrm{Y}_{2} \mathrm{O}_{3}$ scattering/absorption loss at $248 \mathrm{~nm}$ on single-1ayer coating thickness. 


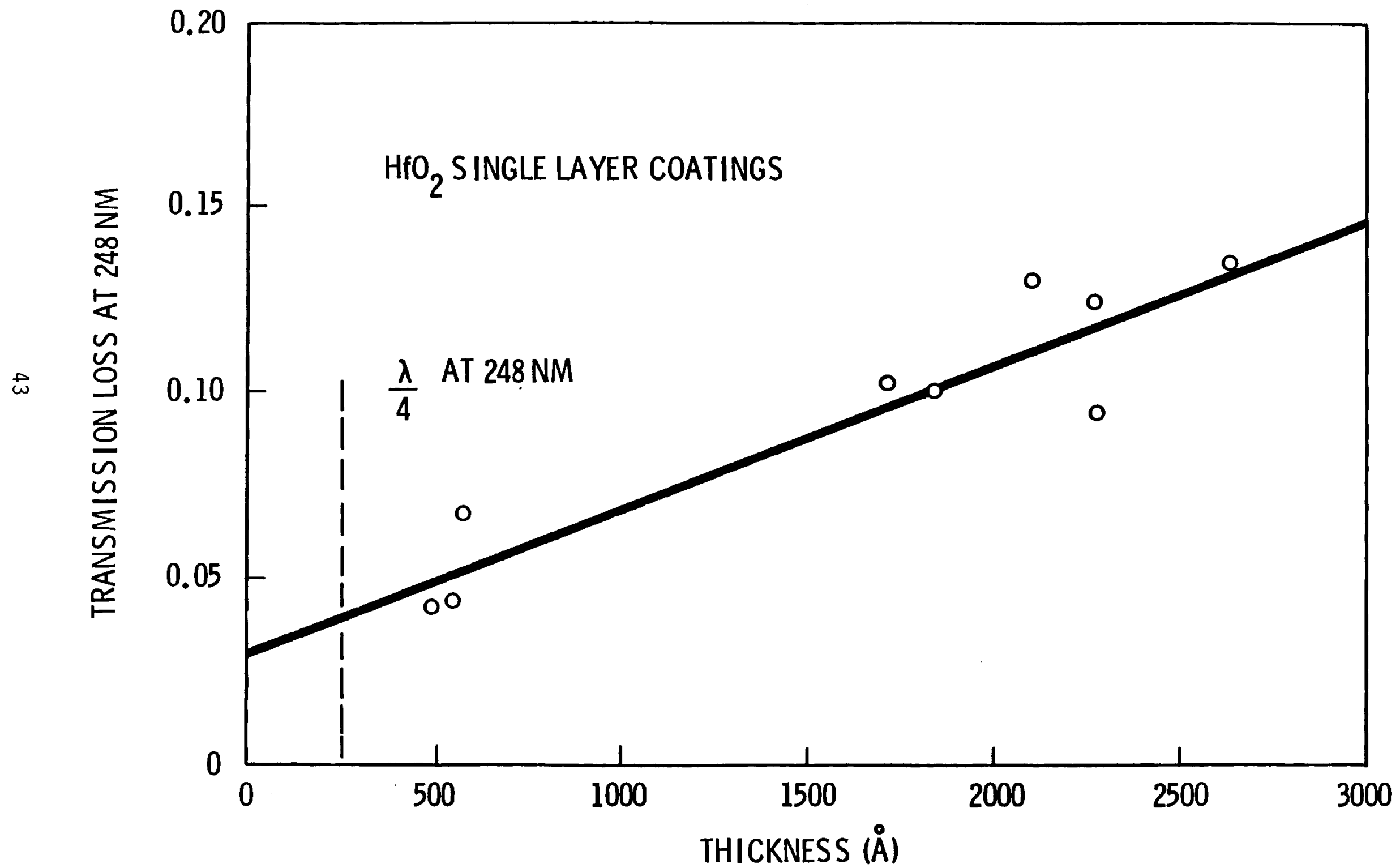
Figure 16. Dependence of $\mathrm{HfO}_{2}$ scattering/absorption loss at $248 \mathrm{~nm}$ on single-layer
coating thickness. 


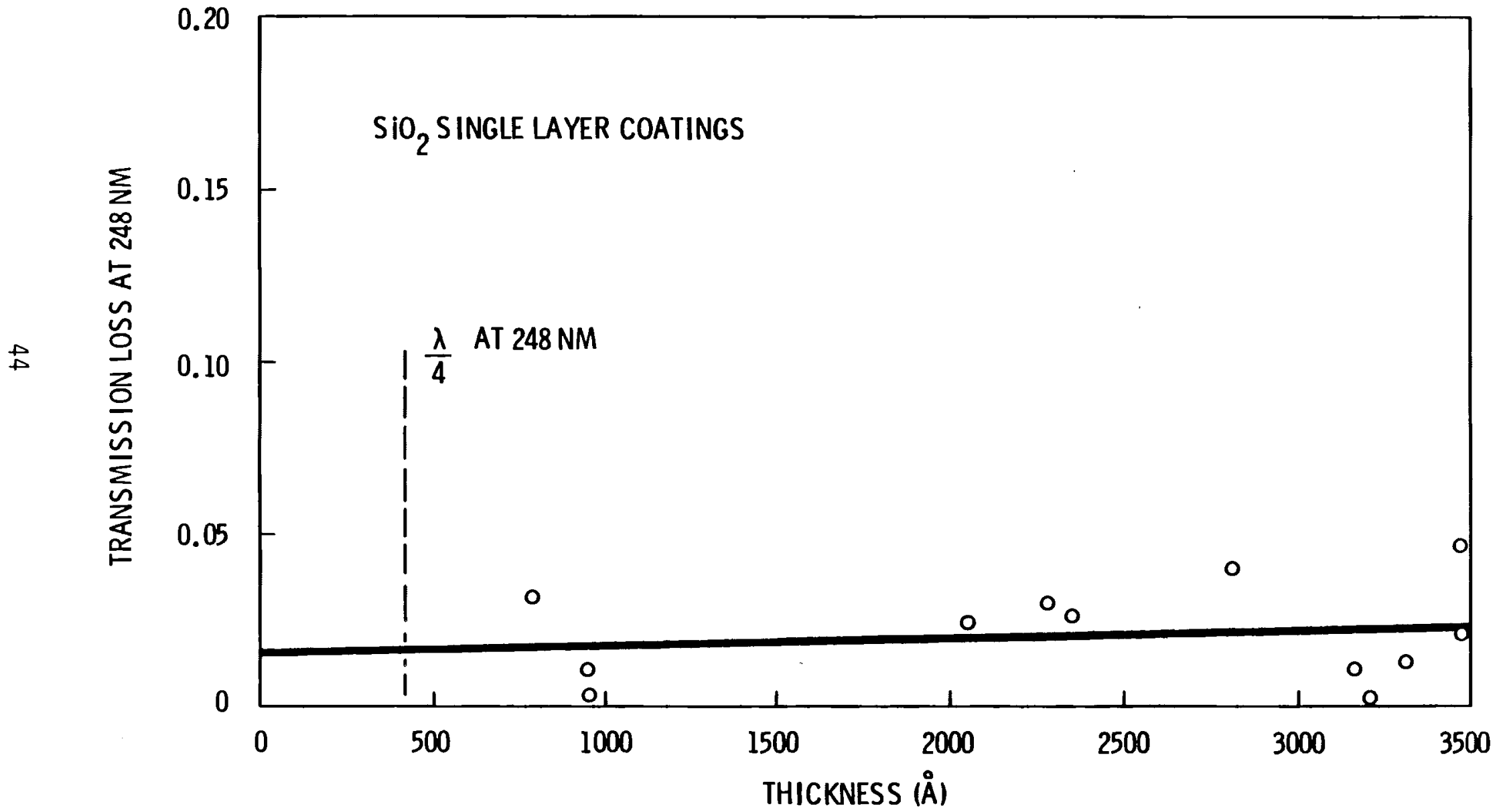

Figure 17. Dependence of $\mathrm{SiO}_{2}$ scattering/absorption loss at $248 \mathrm{~nm}$ on single-layer coating thickness? 


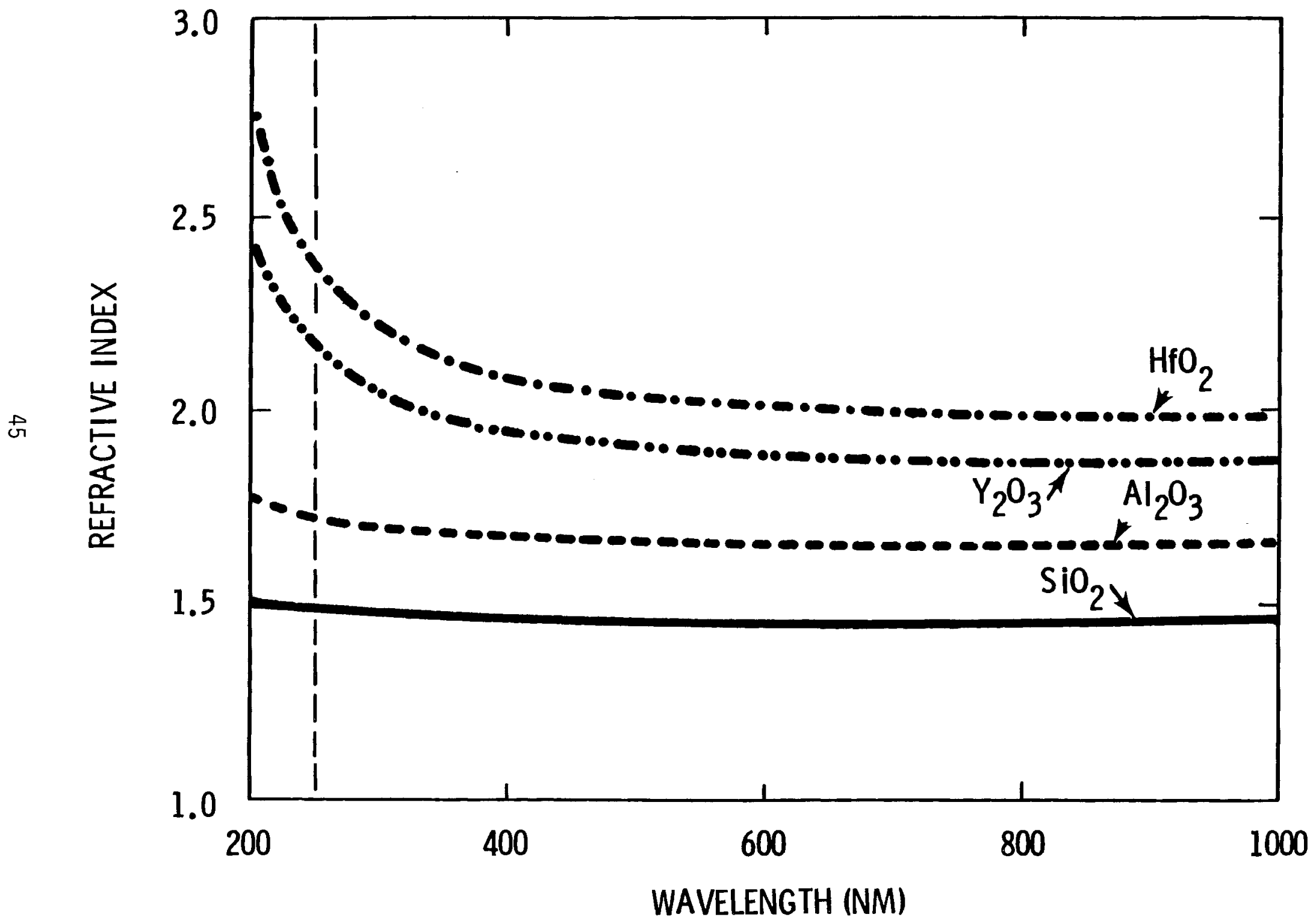

Figure 18. Refractive index variation with wavelength for $\mathrm{HfO}_{2}, \mathrm{Y}_{2} \mathrm{O}_{3} \cdot \mathrm{Al}_{2} \mathrm{O}_{3}$ and $\mathrm{SiO}_{2}$. 


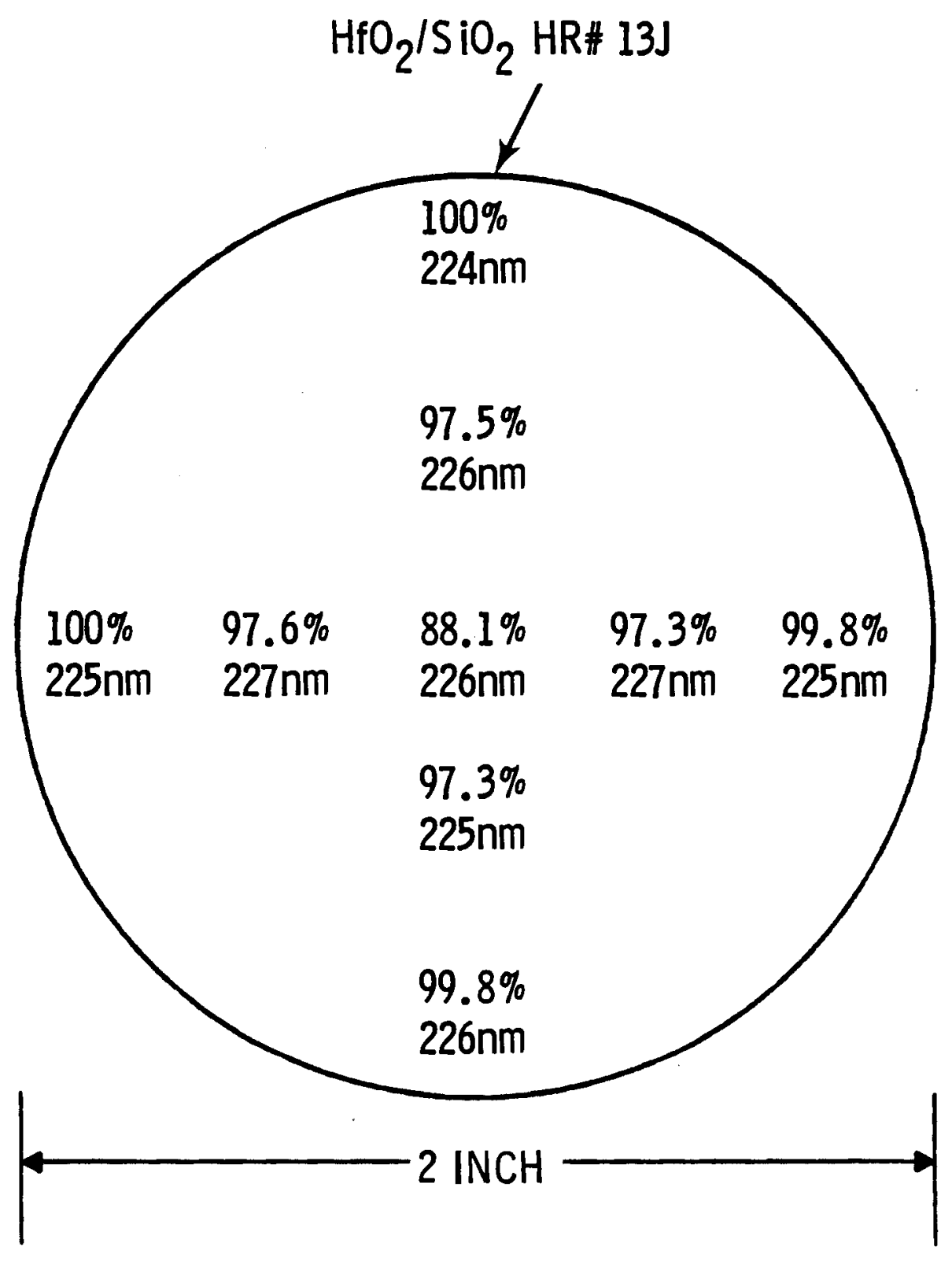

Figure 19. Reflectivity and tuned wavelength profile for a typical two-inch diameter $\mathrm{HfO}_{2} / \mathrm{SiO}_{2}$ mirror. Note the radial dependence of the reflectivity. 


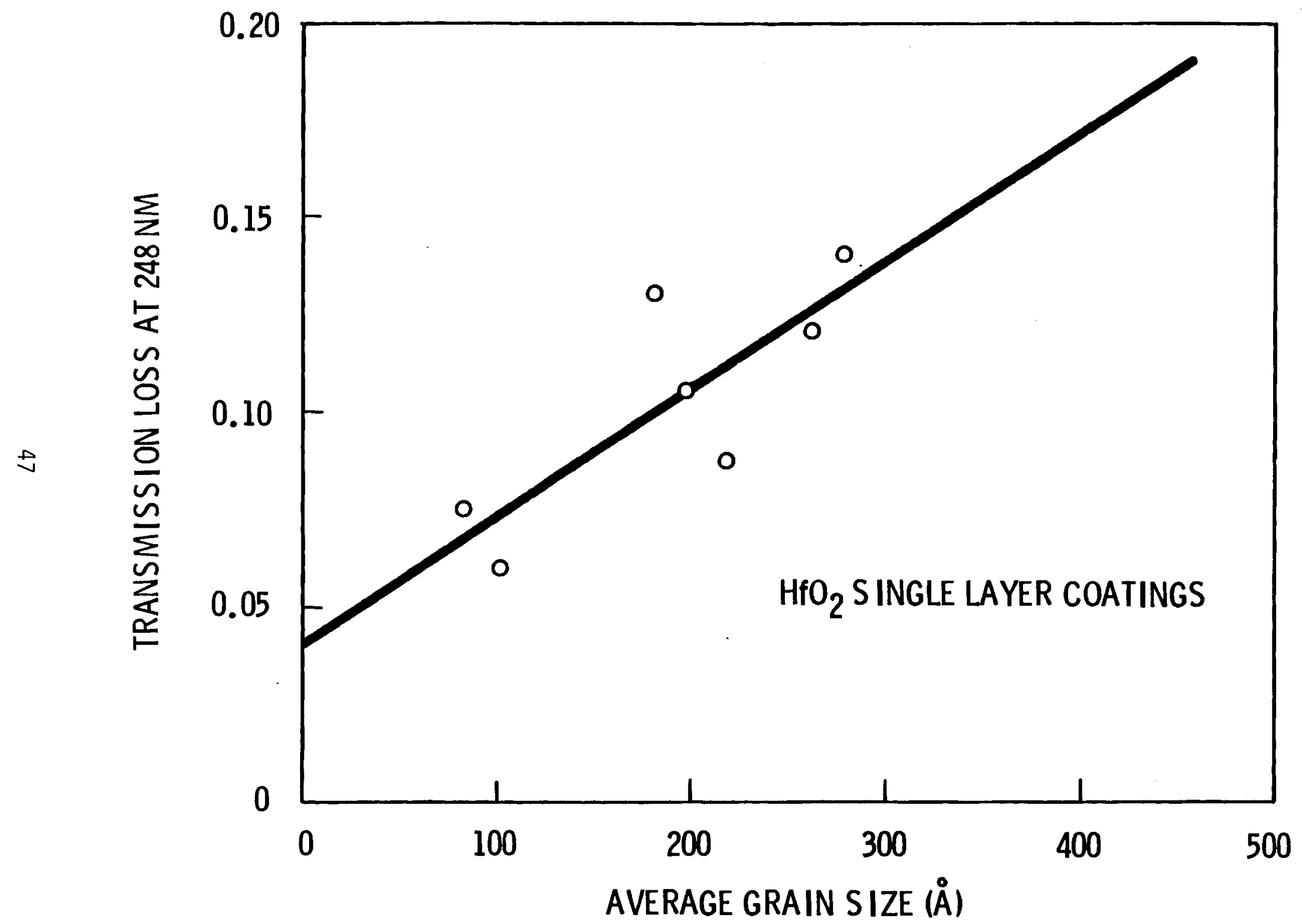

Figure 20. Influence of grain size on transmission loss due to scattering at $248 \mathrm{~nm}$ for approximately constant coating thickness of $2500 \AA$. 


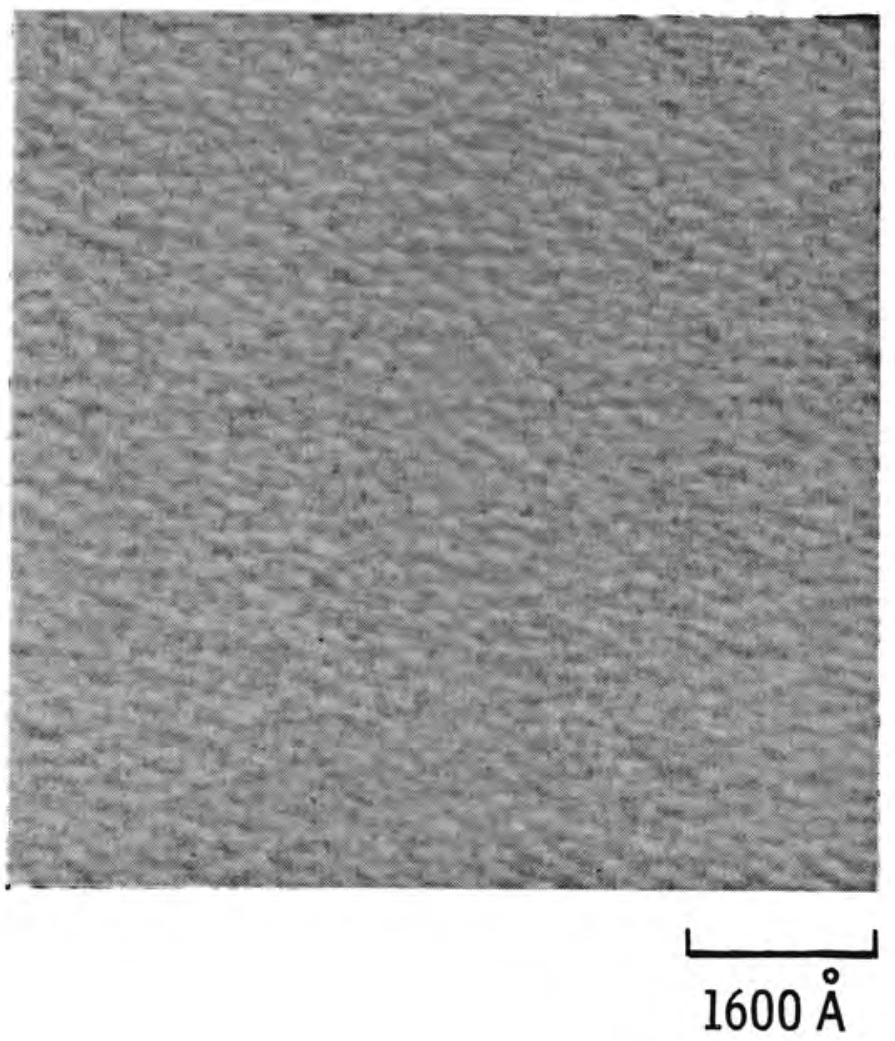

Figure 21. SEM micrograph of the surface topography of a 23 -layer $\mathrm{Y}_{2} \mathrm{O}_{3} / \mathrm{SiO}_{2}$ mirror. 


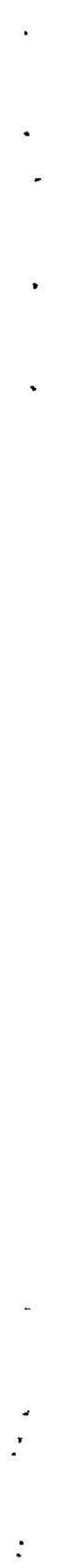


APPENDIX

OXIDE OPTICAL COATINGS FOR THE ULTRAVIOLET 


\title{
OXIDE OPTICAL COATINGS FOR THE ULTRAVIOLET
}

\author{
Compiled from the literature by W.T. Pawlewicz \\ Pacific Northwest Laboratory \\ May, 1980

\section{SUMMARY}

The recent literature is reviewed to compile a list of candidate oxide optical coating materials for use in high power ultraviolet (UV) lasers operating near $250 \mathrm{~nm}$ wavelength. The list includes representative absorption edge and refractive index values for both bulk and thin film oxides, as well' as other potentially important properties of the materials such as hygroscopicity, toxicity, radioactivity, cost, etc. Eleven simple oxides which transmit at $\leq 250 \mathrm{~nm}$ are identified as prime candidates. The prime candidates are the common oxides of $\mathrm{Si}, \mathrm{Al}, \mathrm{Be}, \mathrm{Mg}, \mathrm{Zr}, \mathrm{Hf}, \mathrm{Sc}, \mathrm{Y}, \mathrm{La}$, Nd and $\mathrm{Th}$, which cover a range of refractive indices from 1.5 to 2.5 near $250 \mathrm{~nm}$. The absorption edge values reported for coatings are found to lie at longer wavelengths than those reported for bulk materials. The difference apparentiy results from impurities, stoichiometric deviations and scattering in the coatings, and suggests that improvements in state-of-the-art coating technology will be necessary to realize the absorption edge values for bulk materials. A scarcity of data for wavelengths below $200 \mathrm{~nm}$ is also noticeable in the compilation for coatings, making it difficult to discern the absorption edges presently attainable. The oxides of $\mathrm{Ca}, \mathrm{Sr}, \mathrm{Ba}$, $\mathrm{Pr}, \mathrm{Sm}, \mathrm{Gd}, \mathrm{B}, \mathrm{Ga}, \mathrm{Ge}$ and $\mathrm{Li}$ are also listed as candidates because they transmit in the UV. However, very little optical coating research has been done to date with these materials and more study is required to assess there usefulness for UV applications. A final group of oxides deserving serious consideration is the mixed oxides consisting of two or more simple oxides combined in the appropriate proportions to form intermediate compounds, solid solutions and insoluble systems. Candidate oxides in this class are too numerous to list, but include materials such as $\mathrm{MgAl}_{2} \mathrm{O}_{4}\left(\mathrm{MgO} \cdot \mathrm{Al}_{2} \mathrm{O}_{3}\right)$ and $\mathrm{Y}_{4} \mathrm{Al}_{2} \mathrm{O}_{9}\left(2 \mathrm{Y}_{2} \mathrm{O}_{3} \cdot \mathrm{Al}_{2} \mathrm{O}_{3}\right)$. These mixed oxides generally exhibit absorption edges and refractive index values nearly identical to their constituent simple oxides, but may not exhibit undesirable physical properties of the constituent simple oxides such as hygroscopicity, color centers near $250 \mathrm{~nm}$, etc. 
OXIDE OPTICAL COATING MATERIALS FOR THE ULTRAVIOLET

Data Obtained from the Literature by W.T. Pawlewicz $(5-80)$

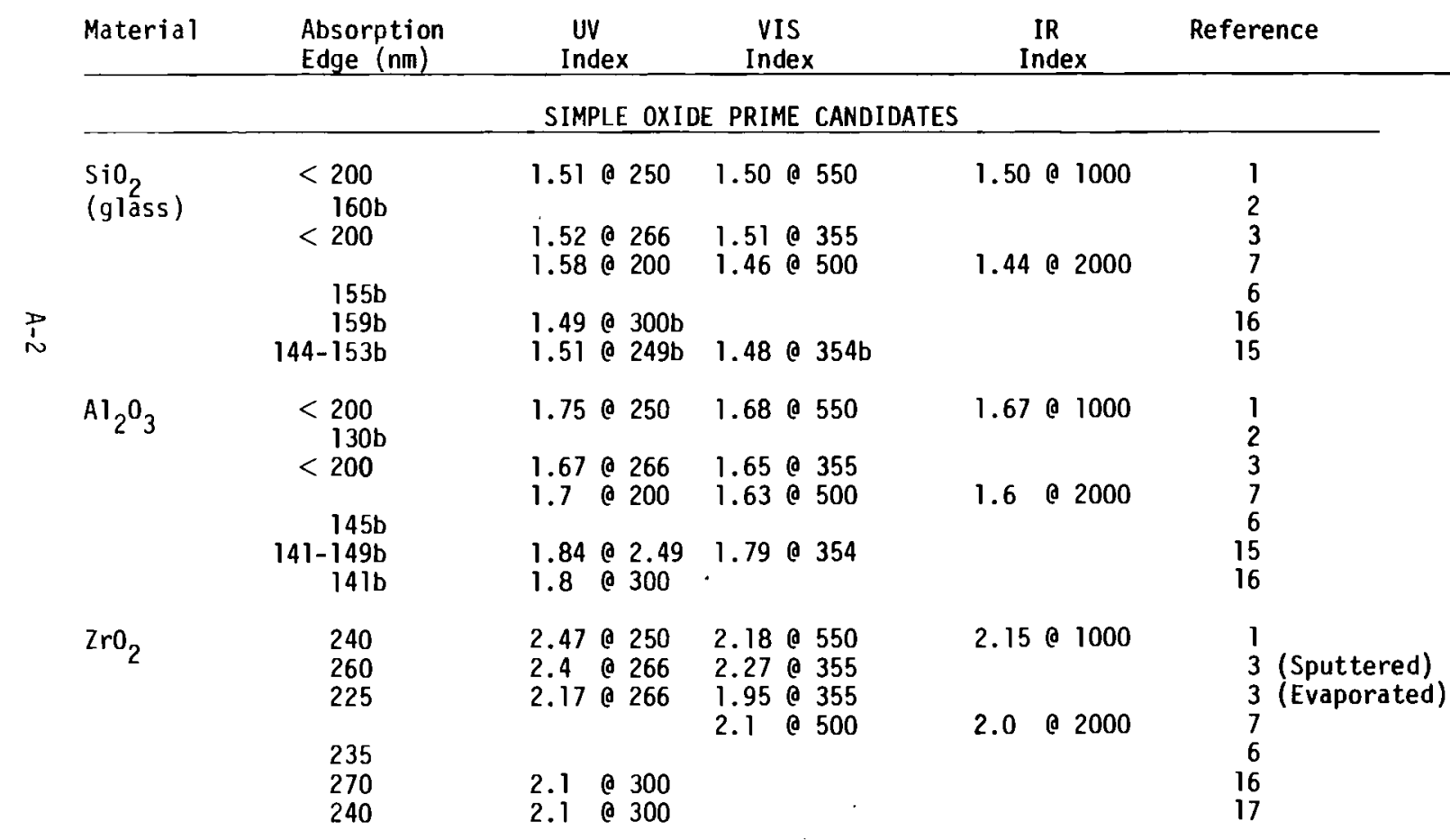

$\mathrm{b}=$ bulk material value 
Page 2

\begin{tabular}{|c|c|c|c|c|c|}
\hline Material & $\begin{array}{l}\text { Absorption } \\
\text { Edge (nm) }\end{array}$ & $\begin{array}{l}\text { UV } \\
\text { Index }\end{array}$ & $\begin{array}{l}\text { VIS } \\
\text { Index }\end{array}$ & $\begin{array}{l}\text { IR } \\
\text { Index }\end{array}$ & Comments (Ref.) \\
\hline \multicolumn{6}{|c|}{ SIMPLE OXIDE PRIME CANDIDATES } \\
\hline $\mathrm{HfO}_{2}$ & $\begin{array}{l}220 \\
230\end{array}$ & & $2.08 @ 355$ & & \\
\hline & $\begin{array}{l}240 \\
225\end{array}$ & 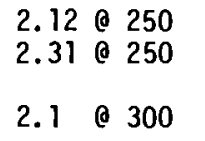 & $\begin{array}{l}1.98 @ 500 \\
2.05 @ 500 \\
2.14 @ 350\end{array}$ & $\begin{array}{l}1.95 @ 1000 \\
1.97 @ 1000\end{array}$ & $\begin{array}{l}14 \text { (After bake) } \\
14 \text { (Before bake) } \\
16 \\
17\end{array}$ \\
\hline$Y_{2}{ }^{0}{ }_{3}$ & 200 & $\begin{array}{l}2.0 \bigcirc 266 \\
1.88 @ 250 \\
1.98 @ 250\end{array}$ & $\begin{array}{l}1.79 \text { @ } 355 \\
1.88 \text { O } 500 \\
2.06 \text { 0 } 500 \\
1.78 \text { 0 } 500 \\
1.820500\end{array}$ & $\begin{array}{l}1.75 \text { @ } 1000 \\
1.7801000\end{array}$ & $\begin{array}{l}3 \text { Hygroscopic starting materials (4) } \\
4 \text { (Thin Films) } \\
4 \text { (Thick Films) } \\
14 \text { (After bake) } \\
14 \text { (Before bake) } \\
16\end{array}$ \\
\hline \multirow[t]{2}{*}{$\mathrm{La}_{2} \mathrm{O}_{3}$} & 220 & $2.16 \odot 250$ & $\begin{array}{l}1.96 \text { @ } 550 \\
1.850500 \\
2.16 \odot 500\end{array}$ & 1.93 @ 1000 & $\begin{array}{l}6 \text { Low packing density (6) } \\
4 \text { (Thin Films, } 300^{\circ} \mathrm{C} \text { ) } \\
\text { Hygroscopic starting materials (4) } \\
4 \text { (Thick Films, } 20^{\circ} \mathrm{C} \text { ) } \\
\text { Low packing density (4) }\end{array}$ \\
\hline & 210 & $\begin{array}{l}1.92 \text { @ } 250 \\
2.10 \text { @ } 250\end{array}$ & $\begin{array}{l}1.86 \text { @ } 500 \\
1.890500\end{array}$ & $\begin{array}{l}1.8401000 \\
1.83 @ 1000\end{array}$ & $\begin{array}{l}6 \\
14 \text { (After bake) } \\
14 \text { (Before bake) }\end{array}$ \\
\hline $\mathrm{Sc}_{2} \mathrm{O}_{3}$ & $\begin{array}{r}200 \\
210\end{array}$ & $1.9-2.00250$ & & & Expensive \\
\hline
\end{tabular}


Page 3

\begin{tabular}{|c|c|c|c|c|c|c|}
\hline Material & $\begin{array}{l}\text { Absorption } \\
\text { Edge (nm) }\end{array}$ & $\begin{array}{l}\text { UV } \\
\text { Index }\end{array}$ & $\begin{array}{l}\text { VIS } \\
\text { Index }\end{array}$ & $\begin{array}{l}\text { IR } \\
\text { Index }\end{array}$ & Reference & Comments (Ref.) \\
\hline
\end{tabular}

SIMPLE OXIDE PRIME CANDIDATES

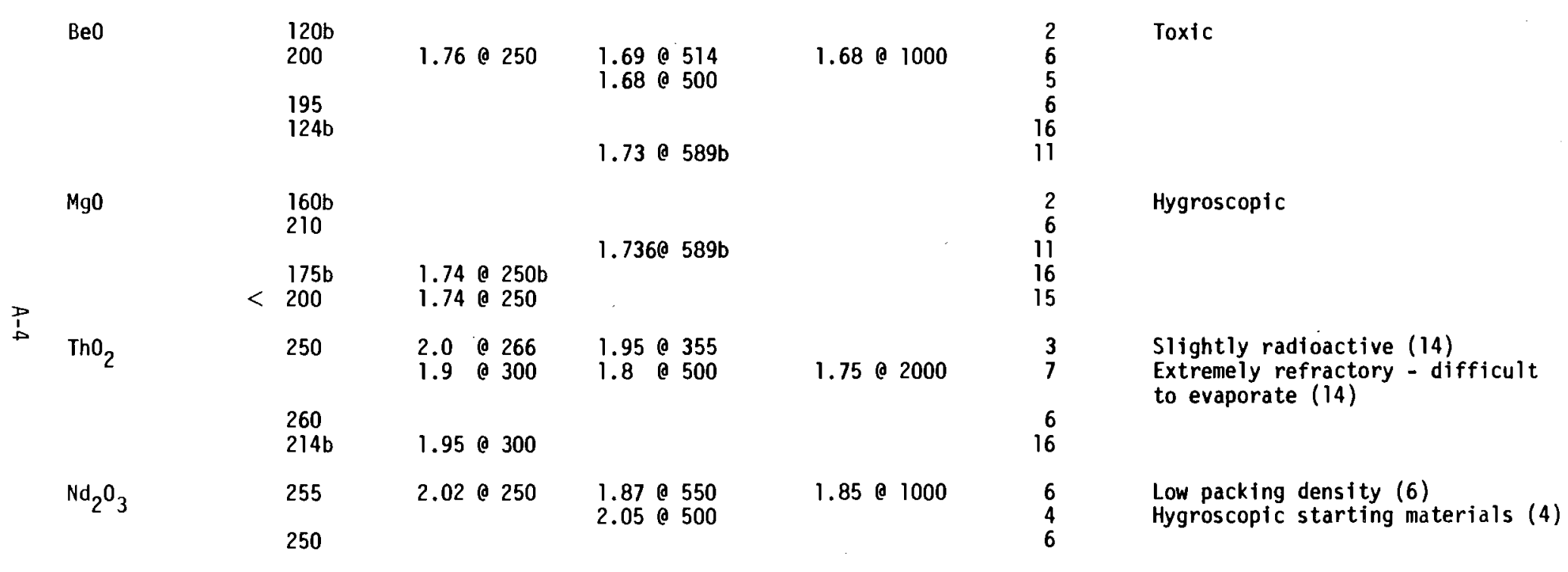

$\bar{b}=$ bulk material value 
Page 4

\begin{tabular}{|c|c|c|c|c|c|c|}
\hline Material & $\begin{array}{l}\text { Absorption } \\
\text { Edge (nm) }\end{array}$ & $\begin{array}{l}\text { UV } \\
\text { Index }\end{array}$ & $\begin{array}{l}\text { VIS } \\
\text { Index }\end{array}$ & $\begin{array}{l}\text { IR } \\
\text { Index }\end{array}$ & Reference & Comments (Ref.) \\
\hline \multicolumn{6}{|c|}{ CANDIDATES, BUT REQUIRE MORE STUDY } & \\
\hline
\end{tabular}

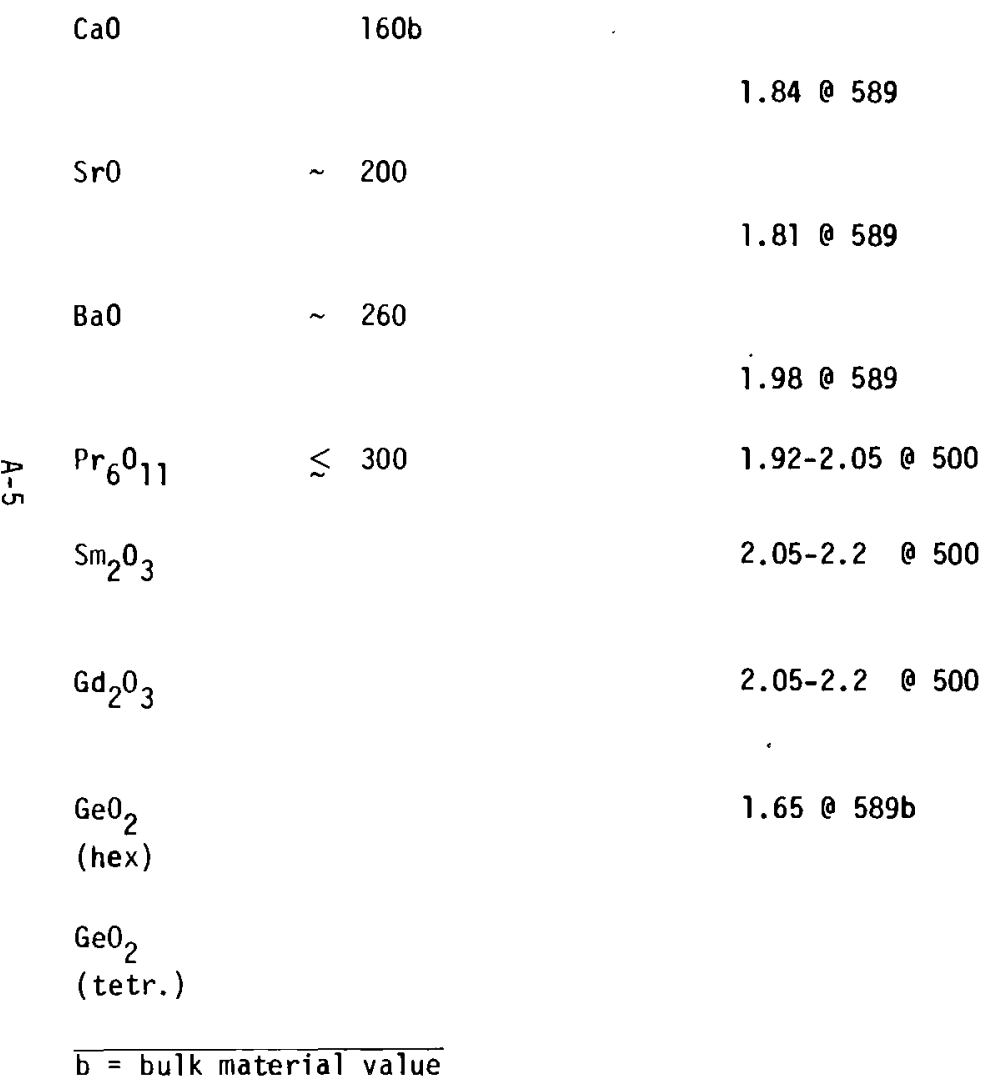

2 Soluble: $0.13 \mathrm{~g} / \mathrm{loOg} \mathrm{H} \mathrm{H}_{2} \mathrm{O}$

11

13 Soluble: $0.69 \mathrm{~g} / 100 \mathrm{~g} \mathrm{H} \mathrm{H}_{2} \mathrm{O}$

11

13 Soluble: $3.48 \mathrm{~g} / 100 \mathrm{~g} \mathrm{H} \mathrm{H}_{2} \mathrm{O}$

11

$4 \quad$ Hygroscopic starting materials (4)

4 Hygroscopic starting materials (4) Deposition uncontrolled (4) Absorptive (4)

$4 \quad$ Hygroscopic starting materials (4) Deposition uncontrolled (4) Absorptive (4)

11 Soluble: $\begin{aligned} & 0.447 \mathrm{~g} / 100 \mathrm{~g} \mathrm{H} \mathrm{H}_{2} \mathrm{O} \mathrm{O} \\ & 20^{\circ} \mathrm{C}(11)\end{aligned}$

Insoluble (11) 
Page 5

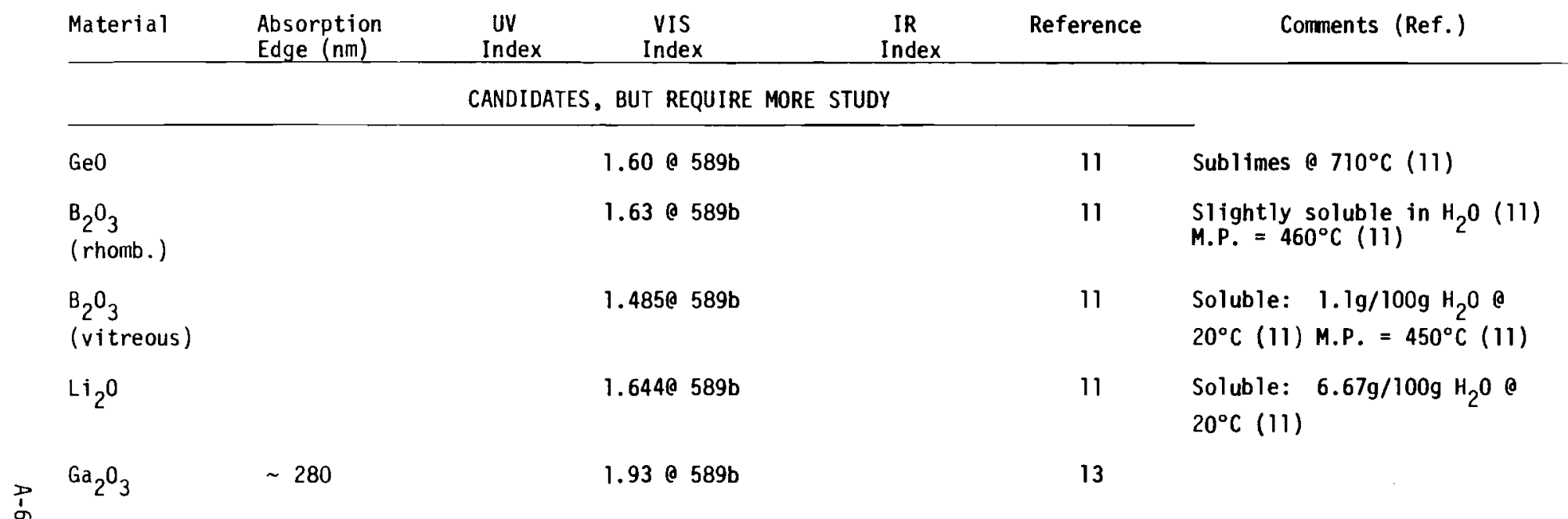

MIXED OXIDE PRIME CANDIDATES

$\begin{array}{llllll}\mathrm{MgAl}_{2} \mathrm{O}_{4} & 225 & 1.90 @ 250 & 1.64 \odot 500 & 1.61 \oplus 1000 & 1 \\ \left(\mathrm{MgO} \cdot \mathrm{Al}_{2} \mathrm{O}_{3}\right) & & & & \\ \mathrm{Y}_{4} \mathrm{Al}_{2} \mathrm{O}_{9} & 220 & 1.97 @ 250 & 1.78 @ 500 & 1.7601000 & 1 \\ \left((2) \mathrm{Y}_{2} \mathrm{O}_{3} \cdot \mathrm{Al}_{2} \mathrm{O}_{3}\right) & & & & \end{array}$

$\overline{\mathrm{b}}=\overline{\text { bulk material value }}$ 
Page 6

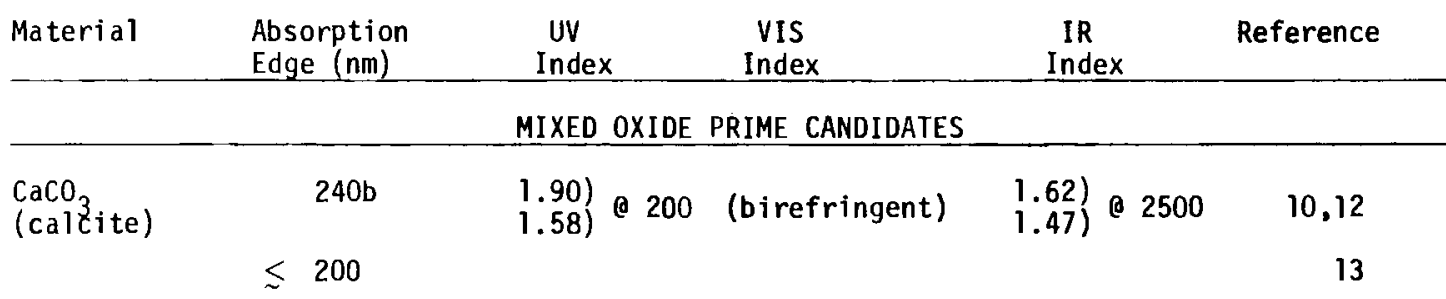

$\mathrm{BeAl}{ }_{2} \mathrm{O}_{4}$

$\left(\mathrm{BeO}-\mathrm{Al}_{2} \mathrm{O}_{3}\right.$ )

+ Numerous unexplored compound-forming systems, solid solutions and insoluble systems formed from the simple oxides listed above. 


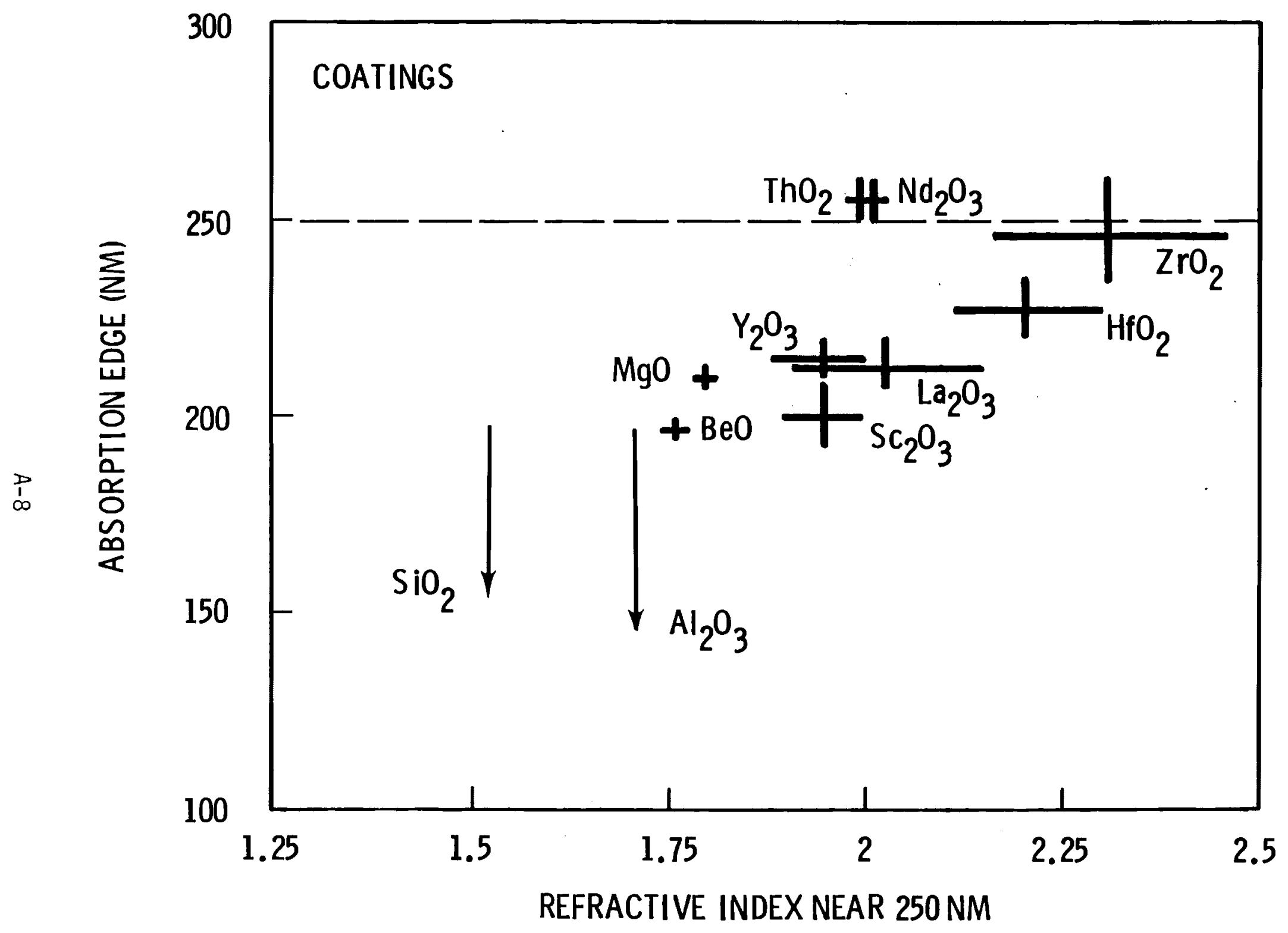




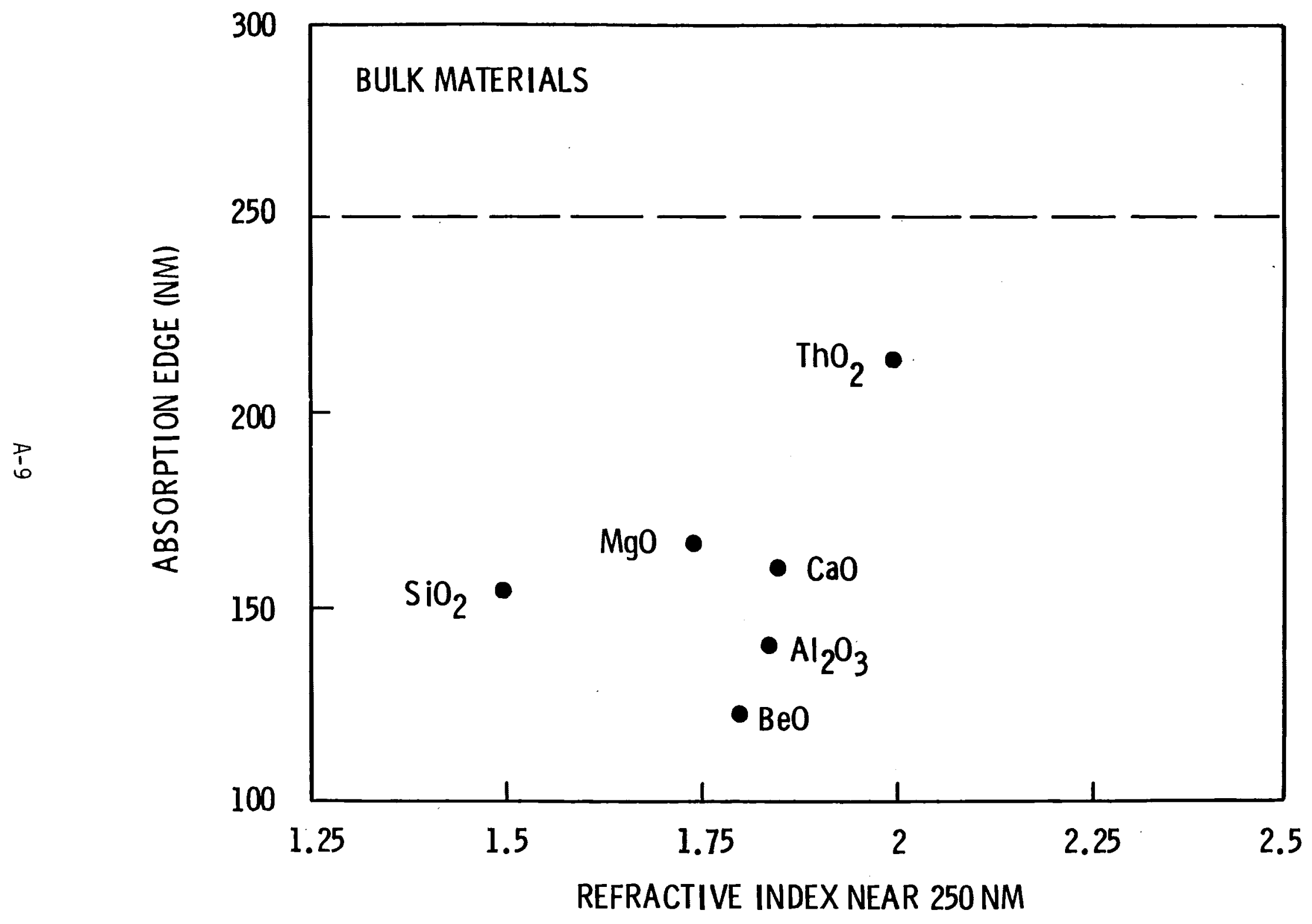


REFERENCES

FOR APPENDIX

1. W.T. Pawlewicz, D.D. Hays and P.M. Martin, "High-Band-Gap Oxides for 0.25 and $1.06 \mu \mathrm{m}$ Fusion Lasers", Thin Solid Films $\underline{73}$ (1980) 169-175.

2. A. Feldman, R.M. Waxler and I.H. Malitson, "Survey of Refractive Data on Materials for High-Power Ultraviolet Laser Applications", in Proceedings of the Society of Photo-Optical Instrumentation Engineers, Vol. 204, Physical Properties of Optical Materials, pp. 95-101.

3. B.E. Newnam and D.H. Gi11, "U1traviolet Damage Resistance of Laser Coatings", in Laser Induced Damage in Optical Materials: 1978 (NBS Spec. Pub. 541), Edited by A.J. Glass and A.H. Guenther, pp. 190-201.

4. G. Hass, J.B. Ramsey and R. Thun, "Optical Properties of Various Evaporated Rare Earth Oxides and Fluorides", J. Opt. Soc. Amer. 49 (2), (1959) $116-120$.

5. H. Gruner, "Einege Tichtoptische Eigenschaften reaktiv aufgedampfter Berylliumoxid-Schichten", Optik 39 (4), (1974) 443-449.

6. H. Küster and J. Ebert, "Pyroelectric Measurement of Absorption in Oxide Layers and Correlation to Damage Threshold", in Laser Induced Damage in Optical Materials: 1979 (NBS Spec. Pub., 568), Edited by A.J. Glass, A.H. Guenther, H. Bennett and B. Newnam, pp. 269-279.

7. G. Hass and E. Ritter, "Optical Film Materials and Their Applications", J. Vacuum Science and Technology $\underline{4}$ (2), (1967).

8. Electronic, Optical and Laser Materials and Components, Adolf Meller Co., Providence, RI.

9. Handbook of Tables for Applied Engineering Science, The Chemical Rubber Co., p. 220.

10. Harshaw Optical Crystals, The Harshaw Chemical Company.

11. Handbook of Chemistry and Physics, The Chemical Rubber Co.

12. Handbook of Optics of the Optical Society of America, W.G. Driscoll and W. Vaughan, eds., (McGraw-Hi11, 1978).

13. American Institute of Physics Handbook, D.E. Gray, ed. (McGraw-Hi11, 1972).

14. P. Baumeister, "Optical Interference Coatings for the Ultraviolet", Final Progress Report to Office of Naval Research, Contract N00014-77-C-0573, (Aug. 1, 1977 to July 31, 1978). 
15. H.E. Bennett, A.D. Baer, R.S. Hughes, V. Rehn and J.L. Stanford, "Ultraviolet Components for High Energy Applications", First Annual Report to DARPA (NWC TP 6015) March 1978.

16. M. Sparks and C.J. Duthler, "Theoretical Studies of High-Power U1traviolet and Infrared Materials", 8th Technical Report, December 1976, DARPA Contract No. DAHC 15-73-C-0127. (Xonics, Inc., Santa Monica, CA, 1976).

17. P. Baumeister, App1. Opt. 15 (1976) 2313. 


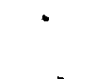




\section{DISTRIBUTION}

No. of

Copies

OFFSITE

A. A. Churm

DOE Patent Division

9800 South Cass Avenue

Argonne, Illinois 60439

20 W. Howard Lowdermilk

Lawrence Livermore National Lab.

Mailstop L-465

P.0. Box 5508

Livermore, CA 94550

27 DOE Technical Information Center

David Milam

Lawrence Livermore National Lab.

Mailstop L-465

P. 0. Box 5508

Livermore, CA 94550

Frank Rainer

Lawrence Livermore National Lab.

Mails top L-465

P.0. Box 5508

Livermore, CA 94550
No. of

Copies

ONSITE
DOE Richland Operations Office

H. E. Ransom

31 Pacific Northwest Laboratory

Walter T. Pawlewicz (20)

Darre11 D. Hays

Peter M. Martin

Ira B. Mann

James W. Patten

Publishing Coordination (2)

Technical Information (5) 


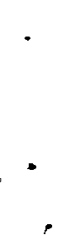

